\title{
GENETIC INVESTIGATIONS AND COUNSELLING ON NEUROGENETIC DISORDERS
}

Ph.D. dissertation

\section{Emese Horváth M.D.}

\author{
Supervisors: \\ Nikoletta Nagy Ph.D. ${ }^{1}$ \\ László Sztriha Ph.D. DSc. ${ }^{2}$ \\ ${ }^{1}$ Department of Medical Genetics \\ ${ }^{2}$ Department of Pediatrics and Child Health Center \\ University of Szeged, SZEGED, HUNGARY
}




\section{Table of contents}

List of publications

1. Introduction 7

1.1. Introduction into neurogenetics 7

1.2. Angelman syndrome 8

1.2.1. Clinical symptoms $\quad 8$

1.2.2. Genetic background 9

$\begin{array}{ll}1.3 . \text { Nemaline myopathy } & 10\end{array}$

1.3.1. Clinical symptoms 10

1.3.2. Genetic background 11

$\begin{array}{lr}\text { 1.4. Hereditary hyperekplexia } & 12\end{array}$

1.4.1. Clinical symptoms $\quad 12$

1.4.2. Genetic background 12

1.5. Aims 14

2. Patients and methods 15

2.1. Patients $\quad 15$

2.1.1. Patient affected by Angelman syndrome $\quad 15$

2.1.1.1. Family of the patient affected by Angelman syndrome 16

2.1.2. Patient affected by nemaline myopathy type 2

2.1.2.1. Muscle biopsy of the patient affected by nemaline myopathy 17

2.1.2.2. Family of the patient affected by nemaline myopathy 18

2.1.3. Patient affected by hereditary hyperekplexia 18

2.1.3.1. Family of the patient affected by hereditary $\begin{array}{ll}\text { hyperekplexia } & 19\end{array}$

2.2. Methods 19

2.2.1. Cytogenetic analysis of chromosomes 20

2.2.2. Chromosome segregation analysis 20

2.2.3. Mutation screening 21

2.2.3.1. Mutation screening in nemaline myopathy type $2 \quad 21$

2.2.3.2. Mutation screening in hereditary hyperekplexia type 122

3. Results 24

3.1. Results in Angelman syndrome 24

3.1.1. Pre-test counselling in Angelman syndrome 24

3.1.2. Genetic investigation revealed paternal isochromosome 15q UPD 25

3.1.3. Post-test counselling in Angelman syndrome 26

3.2. Results in nemaline myopathy 27

3.2.1. Pre-test counselling in nemaline myopathy 27

3.2.2. Genetic investigation revealed parental origin of the mutations 
3.2.3. Post-test counselling in nemaline myopathy 30

3.3. Results in hereditary hyperekplexia 30

3.3.1. Pre-test counselling in hereditary hyperekplexia 30

3.3.2. Genetic investigation revealed heterozygous missense mutation

3.3.3. Post-test counselling in hereditary hyperekplexia

4. Discussion

4.1. Angelman syndrome caused by paternal isochromosome $15 \mathrm{q}$ UPD

4.2. Nemaline myopathy type 2 caused by compound heterozygous mutations with parental origin

4.3. Hereditary hyperekplexia caused by de novo missense mutation

4.4. Difficulties of genetic counselling in neurogenetic disorders

4.5. The future prospect of genetic investigations in neurogenetic

disorders

5. Summary

6. Acknowledgements

7. Electronic-Database Information

8. References

9. Abbreviations

10. Appendix 


\section{List of publications}

\section{Publications directly related to the subject of the dissertation}

I. Emese Horváth, Zsuzsanna Horváth, Dóra Isaszegi, Gyurgyinka Gergev, Nikoletta Nagy, János Szabó, László Sztriha, Márta Széll, Emőke Endreffy: Early detection of Angelman syndrome resulting from de novo paternal isodisomic 15q UPD and review of comparable cases. Mol Cytogenet. 2013;6:35. IPF: 2.360

II. Anna Gajda, Emese Horváth, Tibor Hortobágyi, Gyurgyinka Gergev, Hajnalka Szabó, Katalin Farkas, Nikoletta Nagy, Márta Széll, László Sztriha: Nemaline Myopathy Type 2 (NEM2): Two Novel Mutations in the Nebulin (NEB) Gene. J Child Neurol. 2013 Sep 20. IPF: 1.385

III. Emese Horváth, Katalin Farkas, Ágnes Herczegfalvi, Nikoletta Nagy, Márta Széll: Identification of a novel missense GLRA1 gene mutation in hyperekplexia. J Med Case Reports, under review

\section{Publications indirectly related to the subject of the dissertation}

I. Aranka László, Emese Horváth: Genetic considerations of congenital heart diseases. Magyar Pediater 1989;22:93.

II. Aranka László, Ilona Németh, Emese Horváth: Hyperlipaemia and hyperlipoproteinaemia (HJPL) screening among the children from premature myocardial infaction sick families. Acta Pediatrica Hungarica 1993;31:305-319.

III. Aranka László, Balázs Sümegi, Emese Horváth: Enzymatic diagnosis in mitochondrial myopathies, encephalomyopathies Orvosi Hetilap 1993;135:747-750.

IV. Aranka László, Emese Horváth, Erna Echk, Mátyás Fekete: Serum serotonin, lactate and pyruvate levels in infantile autistic children. Clinica Chemica Acta 1994;1-2:205-207. IPF: 0.958

V. Emese Horváth, Zsuzsanna Csepregi, Aranka László: Level of intelligence in patients with enzymopathies Gyermekgyógyászat 1996;47:213-220.

VI. Emese Horváth, Mária Faragó, Gábor Keszthelyi, Attila Keresztúri, Andrea Szabó, György Szemere, János Szabó: Genetic counselling and care due to taking medications int he first trimester. Orvosi Hetilap 2000;141:1179-1183. 
VII. György Szemere, János Szabó, Mária Faragó, Emese Horváth: Prenatal cytogenetic diagnostics Motesz Magazin 2000;8:17-22.

VIII. János Sikovanyecz, Emese Horváth, Éva Sallay, János Gellén, Attila Pál, János Szabó: Fetomaternal transfusion and pregnancy outcome after cordocentesis. Fetal Diagnosis and Therapy 2001;2:83-89. IPF: 1.142

IX. Kornélia Wajda, Emese Horváth, Júlia Métneki, Hajnalka Ovos, Attila Keresztúri, Dóra Isaszegi, János Szabó: Pre and postnatal ratio of frequent autosomal trisomies. Magyar Nöorvosok Lapja 2001;64:485-489.

X. Kornélia Wajda, Attila Keresztúri, Hajnalka Ovos, Emese Horváth, Attila Pál, László Kovács, János Szabó: Four years experience of first-trimester nuchal translucency screening for fetal aneuploidies with increasing regional availability. Acta Obstet Gyn Scand 2001;80:1104-1109. IPF: 1.209

XI. Hajnalka Orvos, Kornélia Wajda, Zoltán Kozinszky, Márta Katona, Tünde Zoboki, Attila Keresztúri, Emese Horváth, Attila Pál, János Szabó: Thich nucha: early ultrasonograpy signs of cardial anomalies in case of normal caryotype. Magyar Nőorvosok Lapja 2002;65:399-404.

XII. János Sikovanyecz, Emese Horváth, Kornélia Wajda, János Gellén, Attila Pál, János Szabó: Increased nuchal translucency and decreased fetomaternal transfusion after chorionic villus sampling. Ultrasound in Obstetetrics \& Gynecol 2003;21:455-458. IPF: 1.973

XIII. Zsuzsanna Kiss-László, Emese Horváth, János Szöllősi, János Szabó: Y chromosomal microdeletion investigations in patients with azoo- and oligozoosperm. Magyar Andrológia 2003;8:9-11.

XIV. János Sikovanyecz, Hajnalka Orvos, Attila Pál, Márta Katona, Emőke Endreffy, Emese Horváth, János Szabó: Leiden mutation, bed rest and infection: simultaneous triggers for maternal deepvein thrombosis and neonatal intracranial hemorrhage? Fetal Diagnosis and Therapy 2004;19:275-77. IPF: 0.731

XV. Emese Horváth, Attila Keresztúri, János Sikovanyecz, Zsuzsanna Kiss-László, György Szemere, János Szabó: The prevalence of Down syndrome in the southern part of the Great Plain between 1970 and 2003. Gyermekgyógyászat 2005;56:413-418.

XVI. János Sikovanyecz, Emese Horváth, Tímea Ugró, János Gellén, János Szabó, Attila Pál: Foetomaternal transfusion and loss due to amniocentesis or cordocentesis. Magyar Nöorvososk Lapja 2006;69:387-396.

XVII. Katalin H. Nagy, Gyula Soltész, Róbert Hermann, Emese Horváth, Abdulrah Abdulrahman, Péter Sipos: Co-existence of neonatal diabetes and chromosomal surplus. Gyermekgyógyászat 2006;57:71-71. 
XVIII. Emese Horváth, János Sikovanyecz, Irén Haltrich, Mária Hetényi, Zsuzsanna Horváth, Irén Puskás, Márta Katona, Aranka László, György Szemere, János Szabó: Significance of balanced and imbalanced chromosomal translocations in pediatrics. Gyermekgyógyászat 2008;59:94-100.

XIX. Emőke Endreffy, Gábor Kovács, Emese Horváth, Eszter Karg, Aranka László, Sándor Túri: Molecular genetic investigations on a pedigree affected by ectodermal dysplasia. Gyermekgyógyászat 2008;59:85-93.

XX. Márta Katona, Hajnalka Orvos, Krisztina Mader, Emese Horváth, János Szabó, Attila Pál: Diagnostics and therapy of fetal heart diseases. Gyermekgyógyászati Továbbképzö Szemle 2010;1:27-37.

XXI. Emese Horváth, János Sikovanyecz, Mária Hetényi, Zsuzsanna Horváth, Dóra Isaszegi, László Kaiser, János Szabó: Fetal trysomy 17p-11.2. Magyar Nőorvosok Lapja 2010;73:237-242.

XXII. Emese Horváth, János Sikovanyecz, Attila Pál, László Kaiser, Bálint L. Bálint, Szilárd Póliska, Zoltán Kozinszky, János Szabó: Cystic dilatation of aqueductus Sylvii in case of trisomy 17p11.2-pter with the deletion of the terminal portion of the chromosome 6. Case Reports in Medicine 2010:354170.

XXIII. Zsuzsanna Kiss-László, Emese Horváth, János Szöllősi, János Szabó: Y chromosomal microdeletion and MTHFR gene polymorphism in patients with azoo- and oligozoosperm. Magyar Andrologia 2010;15:3-7.

XXIV. János Sikovanyecz, Emese Horváth, Norbert Pásztor, Attila Keresztúri, János Szabó, Attila Pál: Fetomaternal transfusion after amniocentesis and cordocentesis. Irish J Med Sci 2011;180:697701. IPF: 0.581

XXV. János Sikovanyecz, Emese Horváth, Imre Földesi, Zoltán Kozinszky, János Szabó, Attila Pál: Role of the vascular endothelial growth factor in the inverse relationship between increased nuchal translucency thickness and fetomaternal transfusion. J Perinatal Med 2011;39:157-161. IPF: 1.702

XXVI. Dóra Isaszegi, Emese Horváth, Zsuzsanna Horváth, Mária Hetényi, Attila Keresztúri, János Szabó: detection of imbalanced chromosomal translocation with chorionvillus sampling: the difficulties of the metod. Magyar Nöorvosok Lapja 2012;75:4-7.

XXVII. Andrea Szabó, Károly Szili, János Tamás Szabó, Dóra Isaszegi, Emese Horváth, János Sikovanyecz, János Szabó: Ultrasonograpy signs of pranasal thichness and trisomy of chromosome 21 in the second trimester. Magyar Nöorvosok Lapja 2013;76:24-77. 


\section{Introduction}

\subsection{Introduction into neurogenetics}

The field of neurogenetics emerged from advances made in molecular biology, genetics and a desire to understand the link between genes, behavior, the brain, and neurological disorders and diseases. The field started to expand in the 1960s through the research of Seymour Benzer, considered by some to be the father of neurogenetics (Benzer, 1967). His pioneering work with Drosophila helped to elucidate the link between circadian rhythms and genes, which lead to further investigations into other behavior traits (Konopka and Benzer, 1971).

Early analysis relied on statistical interpretation through processes such as LOD (logarithm of odds) scores of pedigrees and other observational methods such as affected sib-pairs, which looks at phenotype and IBD (identity by descent) configuration. Many of the disorders studied on early including Alzheimer's, Huntington's and amyotrophic lateral sclerosis are still at the center of much research to this day (Gershon and Goldin, 1987).

By the late 1980s new advances in genetics such as recombinant DNA technology and reverse genetics allowed the broader use of DNA polymorphisms to test for linkage between DNA and gene defects (Tanzi, 1991). By the 1990s ever advancing technology had made genetic analysis more feasible and available (Simon-Sanchez, 2008). This decade saw a marked increase in identifying the specific role of genes and genetic variations played in relation to neurological disorders (Gajda et al., 2013; Horváth et al., 2013).

Currently there are several neurogenetic disorders, in which causative treatment do not exist. However, neurogenetics is an emerging field that might

yield a causative connection and provide the basis for the development of future novel therapeutic modalities.

In this study, I have summarized the genetic investigations and the difficulties of the genetic counselling on family planning in three neurogenetic 
disorders - Angelman syndrome, nemaline myopathy and hyperekplexia presented in three Hungarian families.

\subsection{Angelman syndrome}

Angelman syndrome (OMIM 105830) is a rare neurodevelopmental disorder. Angelman syndrome has been reported throughout the world among different ethnic groups. Its prevalence is estimated between 1:10000 and 1:20000 (Petersen et al., 1995; Steffenburg et al., 1996; Vercesi et al., 1999).

\subsubsection{Clinical symptoms}

Angelman syndrome is characterized by severe mental and physical delay, limited speech, fine tremor, ataxia, excessive mouthing behavior, fascination with water, jerky limb movements, seizures, craniofacial abnormalities and unusually happy sociable behavior characterized by frequent episodes of inappropriate smiling (Clayton-Smith et al., 2003; Williams et al., 2006). The frequency of the different symptoms is described in Table 1 (Williams et al., 2006).

\begin{tabular}{|l|l|}
\hline Frequency & Symptoms \\
\hline Consistent $(100 \%)$ & $\begin{array}{l}\text { developmental delay, speech impairment, } \\
\text { movement or balance disorder, behavioral } \\
\text { uniqueness }\end{array}$ \\
\hline Frequent $(>80 \%)$ & $\begin{array}{l}\text { delayed growth in head circumference, seizures, } \\
\text { abnormal EEG }\end{array}$ \\
\hline Associated $(20-80 \%)$ & $\begin{array}{l}\text { strabismus, hypopigmented skin and eyes, tongue } \\
\text { thrusting, hyperactive tendon reflexes, feeding } \\
\text { problems during infancy, flexed arms during } \\
\text { walking, prominent mandible, increased sensitivity } \\
\text { to heat, wide mouth, wide-spaced teeth, sleep }\end{array}$ \\
\hline
\end{tabular}




\begin{tabular}{|l|l|}
\hline disturbance, frequent drooling, protruding tongue, \\
attraction to water, excessive chewing behaviors, \\
flat back of head, smooth palms
\end{tabular}

Table 1. The frequency of the symptoms in Angelman syndrome (Williams et al., 2006).

\subsubsection{Genetic background}

Seventy percent of Angelman syndrome cases investigated with molecular genetics methods are the result of a small deletion in the 11-13 region of the maternal chromosome 15. A deletion in the same region of the paternal chromosome 15 results in the sister disorder Prader-Willi syndrome. Expression of the genes in the 11-13 region is regulated by the imprinting center, which differentially silences the paternal copy of the ubiquitin protein ligase E3A $(U B E 3 A)$ gene in the hippocampus and in the cerebellum.

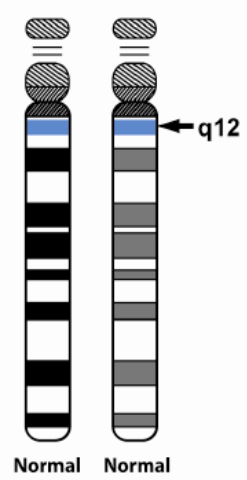

P $\quad \mathbf{M}$

Normal

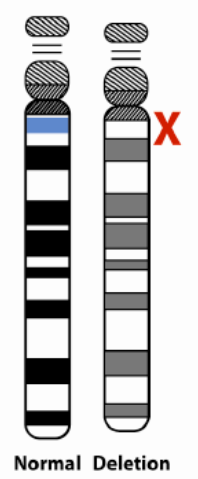

P $\quad \mathbf{M}$

Deletion

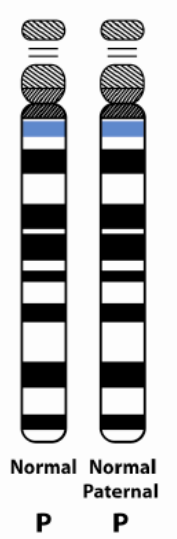

UPD

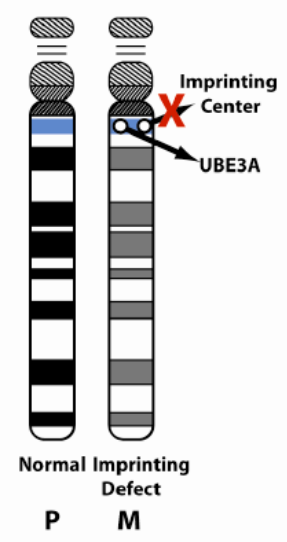

Imprinting Defect

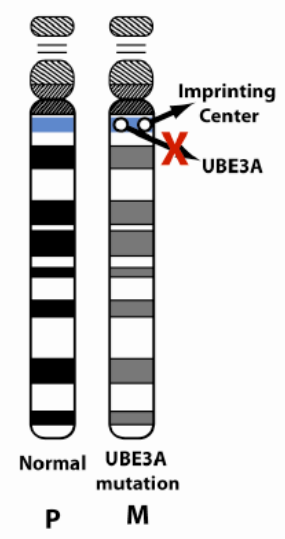

UBE3A Mutation

Figure 1. Schematic drawing of the different mechanisms resulting in Angelman syndrome (Williams et al., 2006). 
Other genetic abnormalities resulting in Angelman syndrome include uniparental disomy (UPD; 5\%), mutations of the imprinting center (5\%), mutations of the UBE3A gene (10\%), and other mechanisms (10\%; Poyatos et al., 2002; Tan et al., 2011; Figure 1.).

\subsection{Nemaline myopathy}

Nemaline myopathy belongs to the group of congenital myopathies, which are a group of genetic muscle disorders with clinical, pathological and molecular heterogeneity (Nance et al., 2012). Nemaline myopathy is a pathologically welldefined subgroup of congenital myopathies characterized by the presence of rodlike structures in the muscle fibers (Wallgren-Petterson et al., 2011). Annual incidence has been estimated at 1:50000 live births in a Finnish study but the disease is more common in the Amish community (Johnston et al., 2000).

\subsubsection{Clinical symptoms}

The nemaline myopathy presents a wide range of clinical variability and severity, although generalized hypotonia, muscle weakness, feeding difficulties and delay of motor milestones are almost always present (Wallgren-Petterson et al., 2011). Its most common form is nemaline myopathy type 2, which is characterized by early onset muscle weakness, which is most pronounced in the axial muscles and proximal limb-girdles. Weakness in facial and bulbar muscles commonly results in dysarthria (Wallgren-Petterson et al., 1989). The course of the disease is non-progressive or slowly progressive and life-expectancy depends on the severity of respiratory-muscle weakness. Mechanical ventilation is necessary for some patients and orthopedic complications are frequent (WallgrenPetterson et al., 1999). Mental development and intelligence are typically within the normal range (Wallgren-Petterson et al., 1999). 


\subsubsection{Genetic background}

All molecularly characterized forms of nemaline myopathy are autosomal, but inheritance can be recessive or dominant, and singleton cases may arise from de novo dominant mutations (North et al., 2011). ) Labeit et al. in 2011 described six genes that have been linked to this condition: $\alpha$-tropomyosin (TPM3)(1q21.3), nebulin $(N E B)(2 q 23.3)$, skeletal muscle $\alpha$-actin $(A C T A 1)(1 \mathrm{q} 42.13), \beta$-tropomyosin (TPM2)(9p13.3), muscle troponin T1 (TNNT1)(19q13.42), cofilin-2 (CFL2)(14q13.1). Two recently identified genes with mutations causing nemaline myopathies are"Kelch-repeat and BTB (POZ) domain containing 13" $($ KBTBD13)(15q22.31), and and kelch-like family member 40 (KLHL40) (3p22.1)

\begin{tabular}{|c|c|c|}
\hline Type & Gene & OMIM ID Number \\
\hline Nemaline myopathy type 1 & $T P M 3(1 q 23.3)$ & $609284(\mathrm{AR} / \mathrm{AD})$ \\
\hline Nemaline myopathy type 2 & NEB(2q23.3) & $256030(\mathrm{AR})$ \\
\hline Nemaline myopathy type 3 & ACTA1(1q42.13) & 161800 (AR/AD) \\
\hline Nemaline myopathy type 4 & $T P M 2(9 p 13.3)$ & $609285(\mathrm{AD})$ \\
\hline Nemaline myopathy type 5 & $T N N T 1(19 q 13.42)$ & $605355(\mathrm{AR})$ \\
\hline Nemaline myopathy type 6 & KBTBD13(15q22.31) & $609273(\mathrm{AD})$ \\
\hline Nemaline myopathy type 7 & CFL2(14q13.1) & $610687(\mathrm{AR})$ \\
\hline Nemaline myopathy type 8 & KLHL40(3p22.1) & $615348(\mathrm{AR})$ \\
\hline
\end{tabular}

Table 2. Summary of the causative genes identified in the background of the different types of nemaline myopathy

Its most common form, the nemaline myopathy type 2 is a rare autosomal recessive condition and develops as the consequence of mutations in the $N E B$ gene 
(OMIM 256030). The $N E B$ gene is located at $2 \mathrm{q} 22$ and encodes nebulin, which is an actin-binding protein (McElhinny et al., 2003). It binds approximately 200 actin monomers (McElhinny et al., 2003). Its length is proportional to thin filament length and it acts as a thin filament regulator and influences thin filament length during sarcomere assembly (McElhinny et al., 2003).

\subsection{Hereditary hyperekplexia}

Hereditary hyperekplexia also known as Stiff baby syndrome (ORPHA3197) is an early-onset neurological disorder characterized by excessive startle responses with violent jerking to sudden, unexpected auditory or tactile stimuli (Kirstein and Silfverskiold, 1958; Ryan et al., 1992). The exact prevalence of hereditary hyperekplexia is unknown. This condition has been identified in more than 70 families worldwide (Lapunzina et al., 2003).

\subsubsection{Clinical symptoms}

Hereditary hyperekplexia usually develops shortly after birth: neonates have prolonged periods of stiffness, clenching fists and attacks of a high-frequency trembling (Kirstein and Silfverskiold, 1958; Ryan et al., 1992). Hereditary hyperekplexia can have severe consequences such as sudden infant death due to laryngospasm and cardiorespiratory failure (Ryan et al., 1992). The symptoms tend to resolve after infancy; however adults may have increased startle-induced falls or nocturnal muscle jerks (Ryan et al., 1992).

\subsubsection{Genetic background}

Hereditary hyperekplexia has a heterogeneous genetic background (Harvey et al., 2008; James et al., 2012). Different mutations in several genes involved in glycinergic neurotransmission can lead to hereditary hyperekplexia, and the

disease exhibits both autosomal recessive and dominant inheritance (Harvey et al., 
2008; James et al., 2012). Mutations in the glycine receptor alpha 1 subunit gene (GLRA1) result in hereditary hyperekplexia type 1 (OMIM149400) and occur in about $30 \%$ of the cases (Rees et al., 1994). Mutations in other genes such as the glycine receptor beta subunit gene (GLRB; OMIM614619; Al-Owain et al., 2012), the glycine transporter solute carrier family 6 member 5 gene (SLC6A5; OMIM614618; Rees et al., 2006), the glycine receptor locator gephyrin gene (GPHN; OMIM603930; Reiss et al., 2001) and the postsynaptic glycine enhancer collybistin gene (ARHGEF9; OMIM300429; Harvey et al., 2004) have also been associated with this clinical condition.

\begin{tabular}{|l|c|c|}
\hline Type & Gene & $\begin{array}{c}\text { OMIM ID } \\
\text { Number }\end{array}$ \\
\hline Hereditary hyperekplexia type 1 & $G L R A 1(5 q 33.1)$ & $149400(\mathrm{AD} / \mathrm{AR})$ \\
\hline Hereditary hyperekplexia type 2 & $G L R B(4 q 32.1)$ & $614619(\mathrm{AR})$ \\
\hline Hereditary hyperekplexia type 3 & $S L C 6 A 5(11 p 15.1)$ & $614618(\mathrm{AD} / \mathrm{AR})$ \\
\hline $\begin{array}{l}\text { Molybdenum cofactor deficiency } \\
\text { type C }\end{array}$ & $G P H N(14 q 23.3)$ & $603930(\mathrm{AD})$ \\
\hline $\begin{array}{l}\text { Early infantile } \\
\text { encephalopathy type 8 epileptic }\end{array}$ & $A R H G E F 9$ & $300429(\mathrm{XR})$ \\
\hline
\end{tabular}

Table 3. Summary of the causative genes identified in the background of the different types of hereditary hyperekplexia (http://www.omim.org/entry/149400).

The most common form of hereditary hyperekplexia is a rare autosomal dominant or autosomal recessive condition and develops as the consequence of mutations in the GLRA1 gene. The GLRAl gene is located at 5q32 and encodes the alpha-1 subunit of the glycine receptor, a ligand-gated chloride channel (Grenningloh et al., 1990). This inhibitory glycine receptor mediates postsynaptic inhibition in the spinal cord and other regions of the central nervous system (Grenningloh et al., 1990). 


\subsection{Aims}

The field of neurogenetics emerged in the 1960s from advances made in molecular biology, genetics and a desire to understand the link between genes, behavior, the brain, and neurological disorders and diseases. Due to the discoveries of the Human Genome Project and the recent technical and methodological developments in genetics and genomics, this decade saw a marked increase in identifying the specific role of genes and genetic variations relating to neurological disorders (Gajda et al., 2013; Horváth et al., 2013).

In this study, my aim was to summarize the genetic investigations and the difficulties of the genetic counselling on family planning in Hungarian families affected by three different neurogenetic disorders: My aim was to investigate a 16month-old Hungarian child, in whom the genetic analysis and the clinical symptoms revealed a rare type of Angelman syndrome and to investigate the parents and help the family in further family planning.

It was also among my goals to investigate the genetic background in a 4year-old Hungarian boy presenting with the clinical and histological findings of nemaline myopathy type 2 . When I started my investigations the mother of the affected child was already expecting her next baby therefore I aimed to investigate the available family members and help the parents with prenatal genetic diagnostic investigations.

I have also aimed to identify the causative genetic abnormalities in a 1year-old Hungarian child with the clinical symptoms of hereditary hyperekplexia type 1 and to investigate the parents and help the family in further family planning.

My investigations have great importance for the affected families since they help family planning. Hopefully, these findings might also provide the basis of future studies for the development of novel therapeutic modalities in neurogenetic disorders. 


\section{Patients and methods}

\subsection{Patients}

\subsubsection{Patient affected by Angelman syndrome}

A 16-month-old Hungarian child was referred to our genetic counseling unit with delayed psychomotor and speech development and dysmorphic features, including wide nasal bridge, low set ears, thick lips, wide mouth with protuberant tongue (Figure 2.). Tongue thrusts were observed. Head circumference was $47 \mathrm{~cm}$ (25 percentile).

The affected child was born at term after an uneventful first pregnancy with normal weight $(3260 \mathrm{~g})$ and head circumference $(33 \mathrm{~cm})$. The Apgar scores were 9, 10 and 10 at 1,5 and 10 minutes, respectively. No signs of decreased fetal movement, neonatal hypotonia or feeding difficulties were reported.

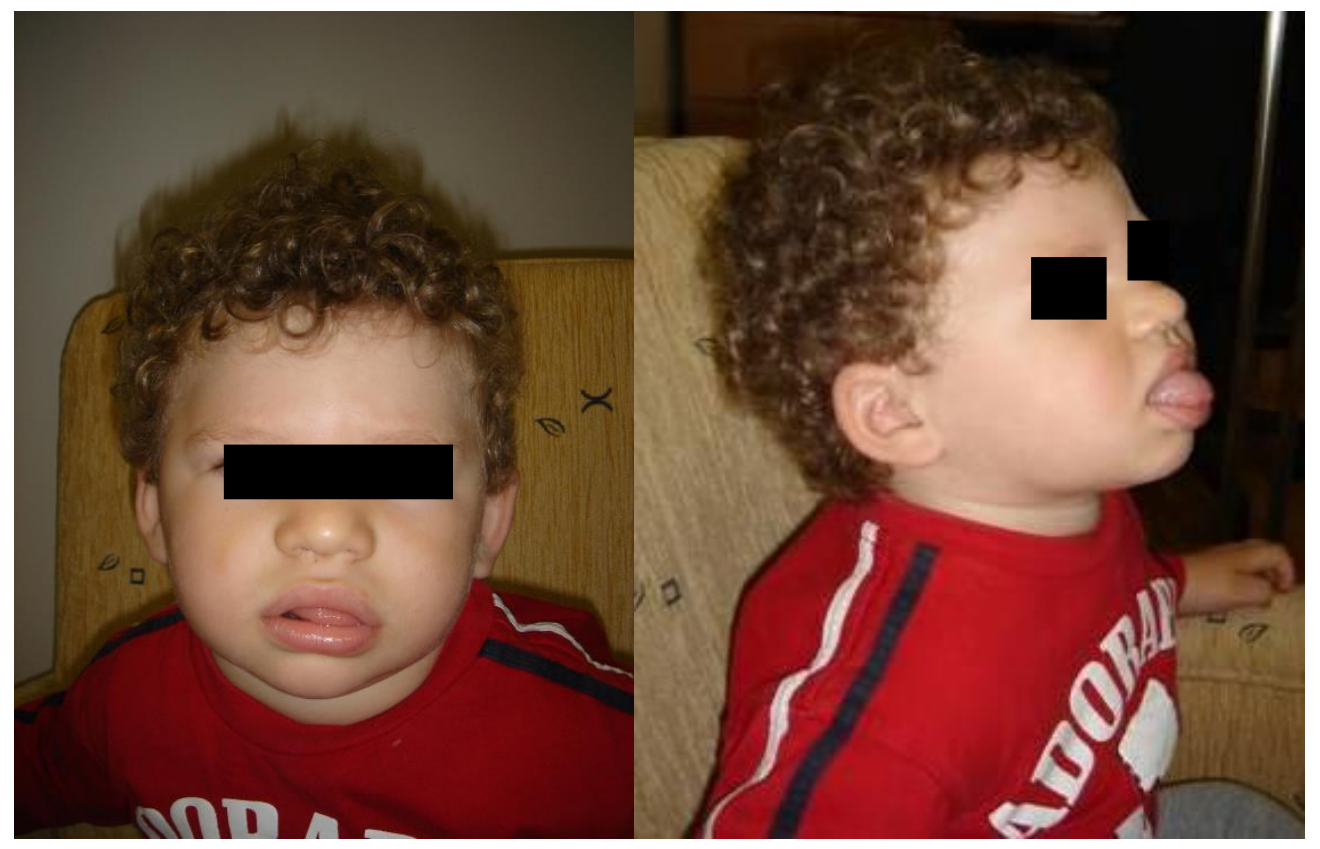

Figure 2. Clinical picture of the patient with Angelman syndrome (Horváth et al., 2013). 


\subsubsection{Family of the patient affected by Angelman syndrome}

The investigated patient was the only affected family member, all the others including the patient's parents were healthy and showed no symptoms of the Angelman syndrome (Figure 3.).

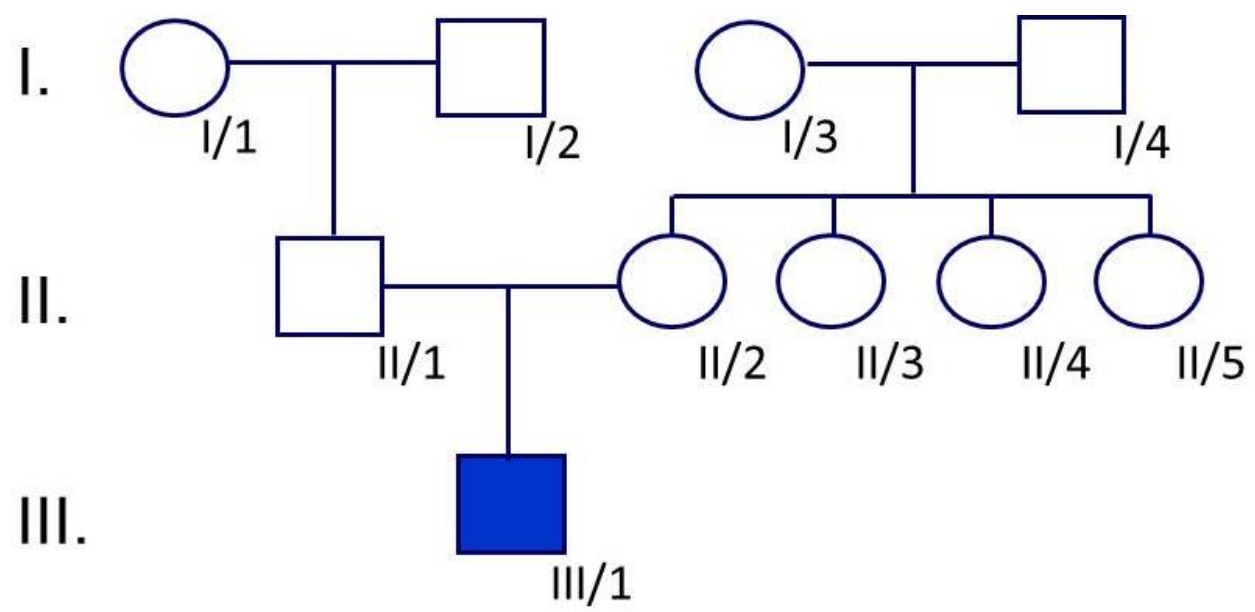

Figure 3. Pedigree of the Hungarian family affected by Angelman syndrome (Horváth et al., 2013).

\subsubsection{Patient affected by nemaline myopathy type 2}

The patient, a boy was born at term from the fourth uneventful pregnancy. Birth weight was $3450 \mathrm{~g}$ and Apgar scores were 9 and 10 at 5 and 10 minutes, respectively. Floppiness and weak cry were noticed in the neonatal period. Generalized hypotonia, weakness and delayed acquisition of motor milestones were observed in early childhood. He began to walk with support at the age of 2 years. Deep tendon reflexes were reduced. There was no fasciculation in the tongue. He suffered also from recurrent respiratory tract infections. The serum creatine kinase activity was normal. The optic fundus and brain MRI were also normal Tandem mass spectrometry and urine gas chromatography screening 
showed no evidence of inborn error of metabolism. Nerve conduction velocity was normal, and electromyography did not show any abnormalities.

The possibility of a congenital myopathy emerged and muscle biopsy was performed at the age of 4 years. Severe respiratory tract infection and pneumonia led to respiratory failure later requiring tracheostomy and mechanical ventilation. His condition improved, however he needs ventilatory support during sleep. Cardiological examination did not show any abnormalities. The patient's cognitive abilities were appropriate for his age.

\subsubsection{Muscle biopsy of the patient with nemaline myopathy}

The histological work up of the muscle biopsy tissue followed standard procedures. The majority of the muscle fibers were hypoplastic or atrophic with large variation in fiber size. Fiber necrosis, regeneration, phagocytosis, or inflammatory cell infiltration were not noted. Gomori's trichrome technique detected prominent red-stained inclusion bodies in the fibers with variation in number and distribution. Gomori trichrome stained sections showed rod-shaped particles in the fibers (Figure 4a).
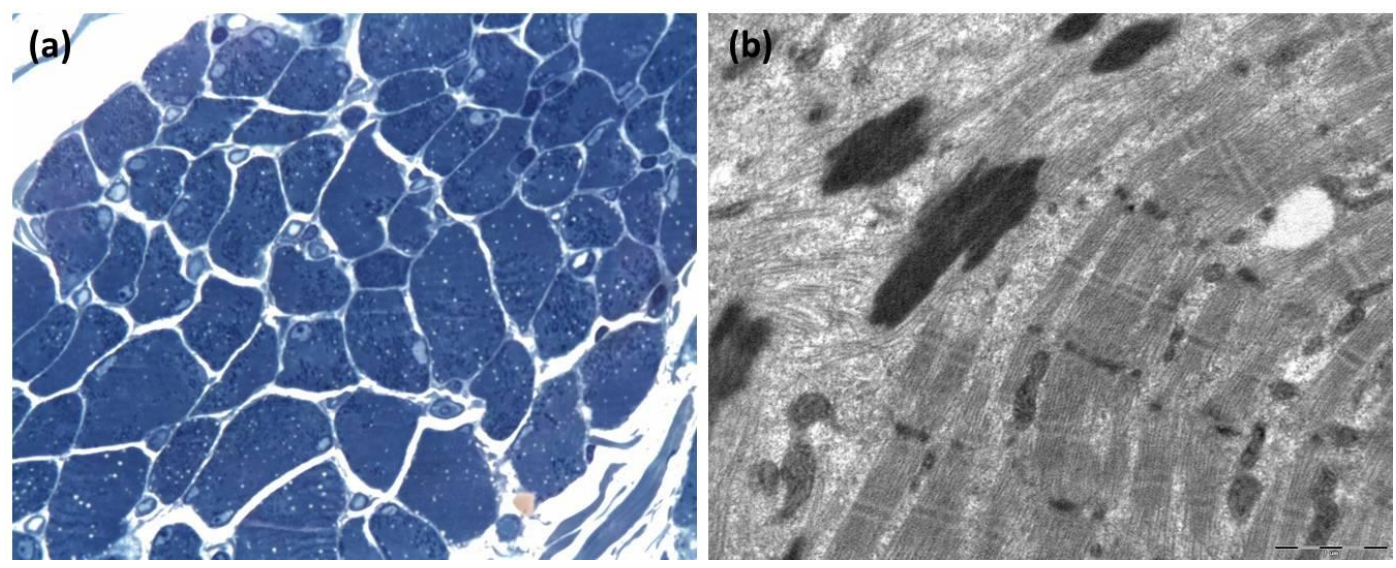

Figure 4. Gomori trichrome stain (a) and electronmicroscopy investigation (b) of the patient with nemaline myopathy type 2 (Gajda et al., 2013). 
Electronmicroscopy revealed that the rods appeared as electron-dense structures localized mainly along the thickened Z-lines (Figure 4b). These rodshaped particles were identified as nemaline rods/bodies, and these findings were consistent with the diagnosis of nemaline myopathy.

\subsubsection{Family of the patient affected by nemaline myopathy}

The patient's parents and his three siblings - one brother and two sisters showed no symptoms of nemaline myopathy type 2 (Figure 5.).

I.

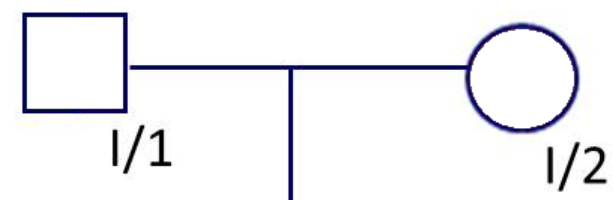

II.
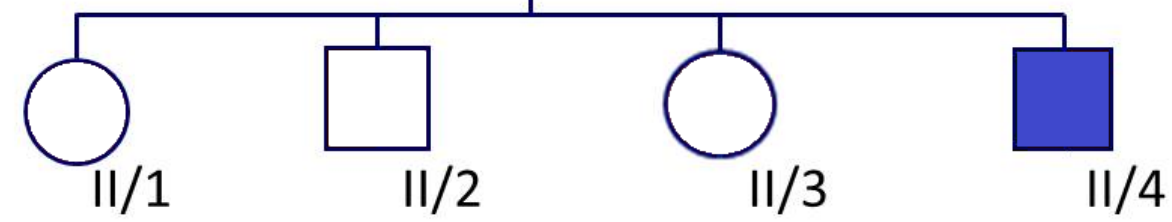

Figure 5. Pedigree of the Hungarian family affected by nemaline myopathy type 2 (Gajda et al., 2013).

\subsubsection{Patient affected by hereditary hyperekplexia}

A male neonate was born on term at the $40^{\text {th }}$ week of gestation by cesarean section delivery after an uneventful pregnancy. His birth weight was $3990 \mathrm{~g}$ and Apgar score was 9/10. At day 1 post-term, he developed pneumothorax and was admitted to the perinatal intensive care unit for extra oxygen and parenteral fluid therapy. At day 4 post-term, abnormal movements, stiffness of the muscles and convulsions were observed, and phenobarbital therapy was initiated. Neurological investigation suggested developmental disturbances of the basal moving circle. At 
day 11 post-term, he was hospitalized in a developmental neurology ward. Examination did not identify hypoxia-induced regulatory abnormalities. The observed recurrent muscular hypertonia was attributed to a suspected ion channel disorder and carbamazepine therapy was initiated.

\subsubsection{Family of the patient affected by hereditary hyperekplexia}

The investigated patient was the only affected family member, the patient's parents were healthy and showed no symptoms of the hereditary hyperekplexia (Figure 6.).

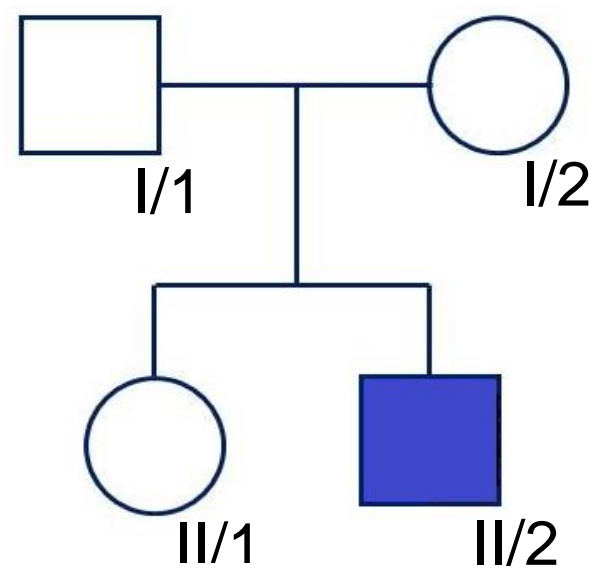

Figure 6. Pedigree of the Hungarian family affected by hereditary hyperekplexia.

\subsection{Methods}

Written informed consents were obtained from all investigated individuals during pre-test genetic counselling before molecular cytogenetic and genetic investigations were carried out. The investigated individuals were informed about the results of the investigations during post-test genetic counselling. The study was conducted according to the Principles of the Declaration of Helsinki. 


\subsubsection{Cytogenetic analysis of chromosomes}

For cytogenetic analysis whole peripheral blood samples of the investigated individuals were used. Blood samples were collected in sterile tubes containing sodium heparin. Whole blood leucocytes separated from red blood cells were placed in culture medium supplemented with serum and antibiotics. Then, mitogen was added to induce mitosis. The cultures were incubated at $37^{\circ} \mathrm{C}$ for 72 hours in an incubator. The cultures have to be shaken at least twice daily which significantly increases mitosis. Then, colchicine was added to the cultures few hours before harvesting to arrest the cells in metaphase. After 72 hours, the centrifuge tubes, in which the cultures were set were centrifuged at $1000 \mathrm{rpm}$ for 10 minutes. Then, the supernatant was discarded and the cells were gently suspended in freshly prepared potassium chloride solution and incubated in an incubator at $37^{\circ} \mathrm{C}$ for about 30 minutes. Then centrifugation was repeated followed by addition of 3:1 methanol and acetic acid, which acted as a fixative. The fixative were washed out to obtain a clear cell button at the bottom of the tube. Then, the chromosomes were prepared by dropping the cell suspension on a clean, grease free slide, where, the drop spread out and the chromosomes got fixed on the slides. Once the slides were prepared, standard G-banding staining technique was carried out and the Cytovision imaging system was used to analysis the staining results.

\subsubsection{Chromosome segregation analysis}

Genomic DNA was extracted from venous blood samples of the investigated individuals. Chromosome 15 segregation analysis with intragenic and extragenic microsatellite markers of the fibrillin gene was performed in all family members using amplified fragment length polymorphism analysis on an ALFexpress instrument (Judge et al., 2001). To determine the molecular background and the recurrence risk, primers for the following microsatellite markers were used in the analysis: D15S119, D15S1028 and MTS-1, -2, -3, -4. 


\subsubsection{Mutation screening}

\subsubsection{Mutation screening in nemaline myopathy type 2}

In view of the morphological findings a search was initiated in collaboration with the commercial diagnostic company, Centogene $\mathrm{GmbH}$ (Rostock, Germany) to find the molecular genetic etiology of nemaline myopathy in the affected child. Tests for ACTA1 and TPM3 were negative. Eventually testing the $N E B$ gene revealed two previously unreported heterozygous mutations: a deletion (c.24527_24528delCT p.P8176fsX8179; Figure 2a) in exon 174 and a duplication (c.24250_24253dupGTCA p.T8085fsX8100; Figure 2b) in exon 171. These mutations result in a frameshift and a premature termination codon, respectively, presumably leading to truncated nebulin protein. Further testing of the parents and their unaffected children was carried out by me in the molecular biology laboratory of the Department of Medical Genetics Institute (Szeged).

Peripheral blood samples were taken from all investigated individuals. Genomic DNA was isolated using a BioRobot EZ1 DSP Workstation (QIAGEN; Hilden, Germany). The exon 171 and 174 of the $N E B$ gene and the flanking introns were amplified by PCR reaction using specific primers (Table 4.).

\begin{tabular}{|l|l|}
\hline Primer & Sequence \\
\hline$N E B$ gene exon 171 forward primer & TCT GGC TCC TTG GAT GAC TG \\
\hline$N E B$ gene exon 171 reverse primer & TGG GAA TGG TGT TAG GCT AGA \\
\hline$N E B$ gene exon 174 forward primer & TGG TTT GGG GCC CTA AAG AT \\
\hline$N E B$ gene exon 174 reverse primer & GGA CAG GGT TAG GAG CAG G \\
\hline
\end{tabular}

Table 4. Primers used to amplify specific regions of the $N E B$ gene. 
The efficacy of the PCR reaction was checked by gel electrophoresis. PCR products were sequenced using ABI Prism 7000 Sequence Detection System (Life Technologies Magyarország Kft; Budapest).

\subsubsection{Mutation screening in hereditary hyperekplexia type 1}

\begin{tabular}{|l|l|}
\hline Primer & Sequence \\
\hline GLRA1 gene exon 1 forward primer & CAA TAG CGC TTT CTG GTT TTG \\
\hline GLRA1 gene exon 1 reverse primer & ACC ACG GAC AGA GGT AGC C \\
\hline GLRA1 gene exon 2 forward primer & TCA CAG CAT GAG AAA GAG CC \\
\hline GLRA1 gene exon 2 reverse primer & CAT TAC CAT GCT GCT TGC TG \\
\hline GLRA1 gene exon 3 forward primer & CCT ACC CTG TGG GTT CTT CC \\
\hline GLRA1 gene exon 3 reverse primer & TGC AGA GGA TAA ATA TTT CAT GGA G \\
\hline GLRA1 gene exon 4 forward primer & CAA AAG TTG ATG TCC TTG GG \\
\hline GLRA1 gene exon 4 reverse primer & GCC TGT TCA CCT CTG TTT GG \\
\hline GLRA1 gene exon 5 forward primer & ACA GCC TCC CTG ATG TGC \\
\hline GLRA1 gene exon 5 reverse primer & AGC TGT GTG GGA ATT TCT GC \\
\hline GLRA1 gene exon 6 forward primer & TGC TTC AAA CAA GTG CTT CTG \\
\hline GLRA1 gene exon 6 reverse primer & ATG ACC TCT GGT CCT GGT TG \\
\hline GLRA1 gene exon 7 forward primer & TCT AAT CCT AAA GCC TTT TGT CC \\
\hline GLRA1 gene exon 7 reverse primer & AGG CAG AGC AAG GAA GTA GG \\
\hline GLRA1 gene exon 8 forward primer & TGT GGG GAA TTA CCG AAG AG \\
\hline GLRA1 gene exon 8 reverse primer & TTG AGA AGG ATG GAC CAT TG \\
\hline GLRA1 gene exon 9 forward primer & AGT GCC TTG CAG GGA GG \\
\hline GLRA1 gene exon 9 reverse primer & ATT CCT GTG CTA TTC CCA CG \\
\hline
\end{tabular}

Table 5. Primers used to amplify specific regions of the GLRAl gene. 
Peripheral blood samples were taken from all investigated individuals. Genomic DNA was isolated using a BioRobot EZ1 DSP Workstation (QIAGEN; Hilden, Germany). The coding regions and the flanking introns of the GLRA1 gene were amplified by PCR reaction using specific primers (Table 5.). The efficacy of the PCR reaction was checked by gel electrophoresis. PCR products were sequenced using ABI Prism 7000 Sequence Detection System (Life Technologies Magyarország Kft; Budapest). 


\section{Results}

\subsection{Results in Angelman syndrome}

\subsubsection{Pre-test counselling in Angelman syndrome}

A 16-month-old Hungarian child with clinical symptoms of a suspected genetic disorder and his family were sent for genetic counselling and cytogenetic and genetic investigations to our institute by the child neurologist. During pre-test genetic counselling the parents were informed about the purpose of the cytogenetic and genetic studies.

The aim of the cytogenetic investigation was to detect any numerical and/or structural abnormalities in the chromosome set of the cells, which can be a putative causative alteration in the background of a genetic syndrome. The parents were also informed about the putative causative alteration of the chromosomes 15 in the background of Prader-Willi/Angelman syndrome. The significance of the investigations was the identification of the genetic cause, which would strongly support the clinical diagnosis and would help to estimate the course and the prognosis of the disease.

The parents were also informed about the method of the cytogenetic investigation and about the time it requires.

Cytogenetic studies were the first choice to elucidate the causative abnormality in the patient with clinical symptoms of delayed speech development and dysmorphic features. After the detection of the rearrangement of chromosomes 15 in the patient, further genetic investigations were carried out to analyze the paternal or maternal origin of the alteration.

Besides these details, the parents were also informed about the legal regulations on the cytogenetic and genetic investigations and they gave their written informed consent before the investigations were started. 


\subsubsection{Genetic investigation revealed paternal isochromosome 15q UPD}

Cytogenetic analysis demonstrated a 45,XY, der(15;15)(q10;q10) karyotype (Figure 7.) in all analyzed cells from the 16-month-old patient (III/1, Figure 3.). All metaphase cells displayed 45 chromosomes, suggesting a balanced homologous rearrangement of the long arms of chromosomes 15 . The parent's karyotype was found to be normal, indicating a de novo chromosome rearrangement in the patient.
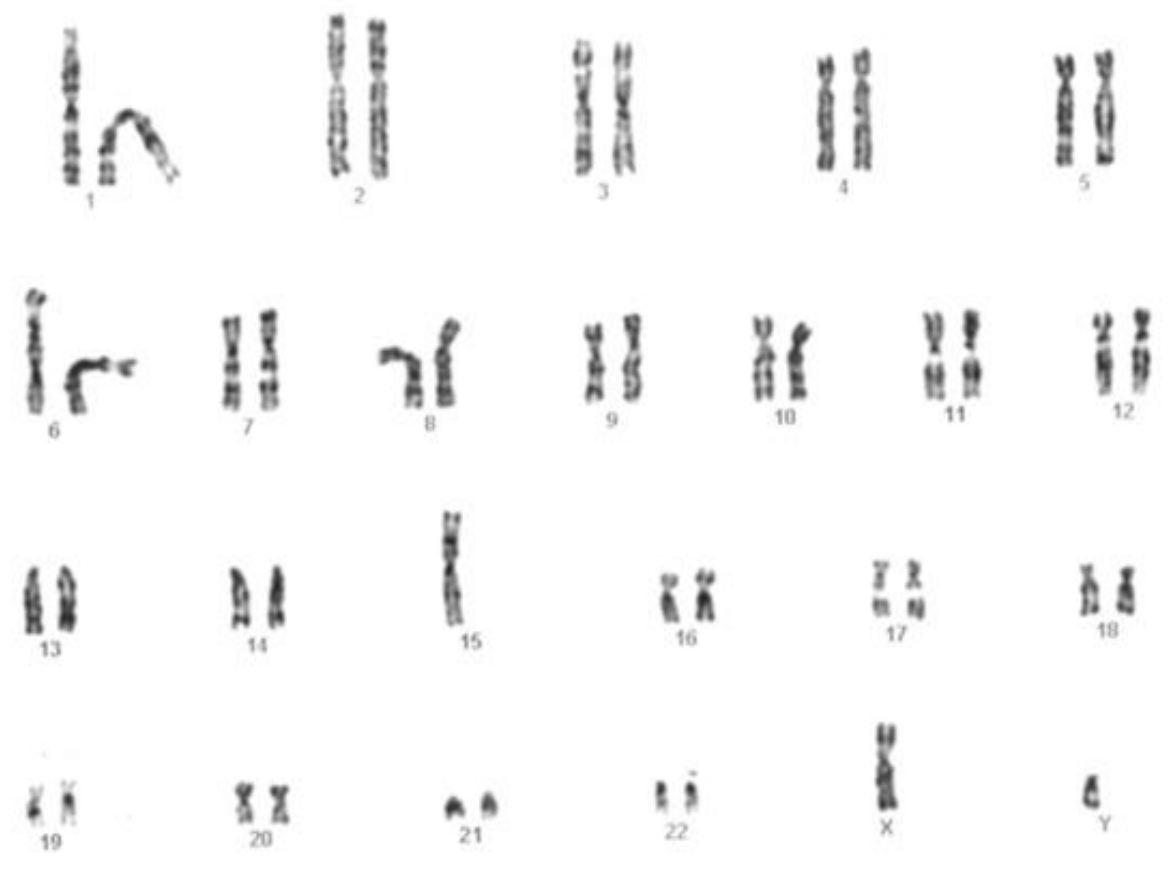

Figure 7. The karyotype of the patient with clinical symptoms of Angelman syndrome.

Analysis of polymorphic STR markers of the fibrillin-1 gene, which is located in 15q21.1, revealed that both long arms of the aberrant chromosome 15 were inherited from the father (Figure 8.), allowing a diagnosis of Angelman syndrome caused by paternal UPD. The patient was homozygous at all loci for 
which his father was heterozygous, indicating that the rearrangement resulted from a isochromosome $15 \mathrm{q}$.

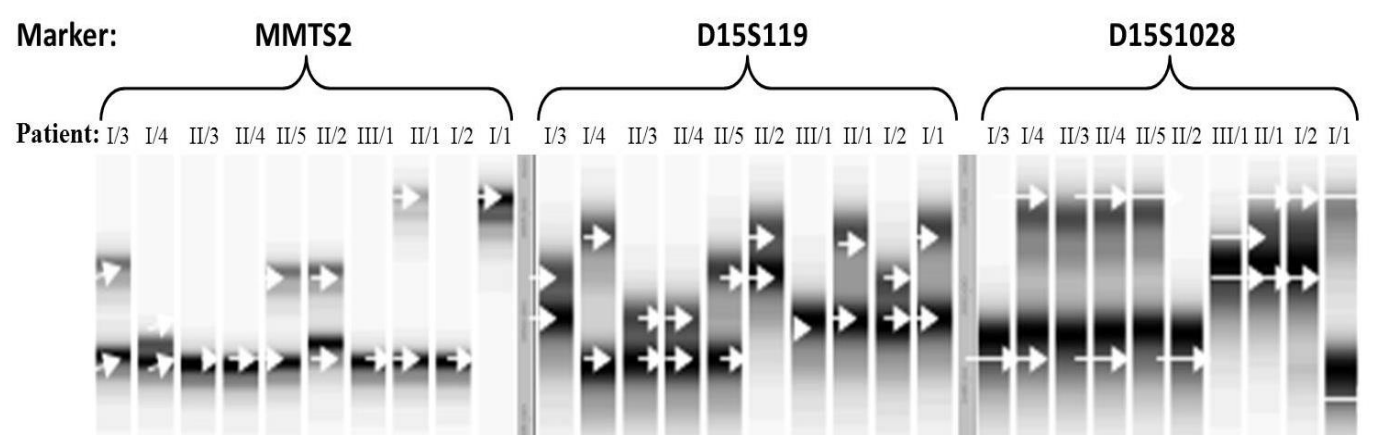

Figure 8. Genetic analysis of the affected family using polymorphic STR markers MTS2, D15S119 and D15S1028 for the fibrillin-1 gene.

\subsubsection{Post-test counselling in Angelman syndrome}

During the post-test genetic counselling, the parents were informed about the balanced structural chromosomal rearrangement 45,XY, $\operatorname{der}(15 ; 15)(\mathrm{q} 10 ; \mathrm{q} 10)$ identified at the affected child. The performed investigations also revealed that the parents are not carriers of the balanced translocation of chromosomes 15, it emerged de novo in the infant. In order to prove the causative relationship between the carrier status of the balanced translocation and the clinical symptoms of the patient further genetic study was performed to identify the parental origin of chromosome 15. It was explained in details for the parents that the paternal origin of chromosome 15 would suggest Angelman syndrome, while its maternal origin would indicate Prader-Willi syndrome and its biparental origin would not likely to cause any clinical symptoms. The performed segregation analysis of chromosome 15 suggested paternal origin and thus Angelman syndrome. The cytogenetic and genetic finding correlated well with the clinical symptoms of the affected child such as the detected minor anomalies, the developmental delay in speech and the sleeping abnormality. According to the literature, Angelman syndrome caused by paternal UPD is less severe in its course and prognosis compared to Angelman syndrome with other causative abnormalities. The importance of the appropriate 
diet was emphasized for the parents, since this form is associated with increased risk of obesity. Regarding family planning, the parents were informed about the very low risk - new mutation rate equivalent - of recurrence, since the identified abnormality emerged de novo in the affected child.

\subsection{Results in nemaline myopathy}

\subsubsection{Pre-test counselling in nemaline myopathy}

The 4-year-old Hungarian child with nemaline myopathy type 2 and his family were sent for genetic counselling and the cytogenetic and genetic investigations to our institute by the child neurologist. The affected child was previously investigated in abroad (Centogene GmbH Rostock, Germany) and two compound heterozygous mutations were identified in the $N E B$ gene (c.24527_24528delCT p.P8176fsX8179 and c.24250_24253dupGTCA p.T8085fsX8100), which were considered as causative abnormalities for nemaline myopathy type 2 . He was referred with his family for genetic counselling and further genetic investigations, since his mother was 9-week-old pregnant and was expecting her fifth baby. Previously the parents and the clinically unaffected brother and sisters of the patient were not investigated.

During pre-test genetic counselling the parents were informed about the purposes of the genetic studies, which were the followings: To verify the presence of the two heterozygous mutations of the NEB gene in the affected child, to identify the possible carrier status of the parents and the unaffected siblings and to provide the option of the prenatal diagnostic testing for the pregnant mother. The parents were also informed about the method of the genetic investigation and about the time it requires.

Besides these details, the parents were also informed about the legal regulations on the genetic investigations and they gave their written informed consent before the investigations were started. 


\subsubsection{Genetic investigation revealed parental origin of the mutations}

Using direct sequencing the performed genetic investigations confirmed the presence of the two compound heterozygous mutations in the $N E B$ gene in the affected child. One of the mutation was a heterozygous deletion (c.24527_24528delCT p.P8176fsX8179) in exon 174, while the other was a heterozygous duplication (c.24250_24253dupGTCA p.T8085fsX8100) in exon 171 (Figure 9.). These mutations result in a frameshift and a premature termination codon, respectively, presumably leading to truncated nebulin protein.
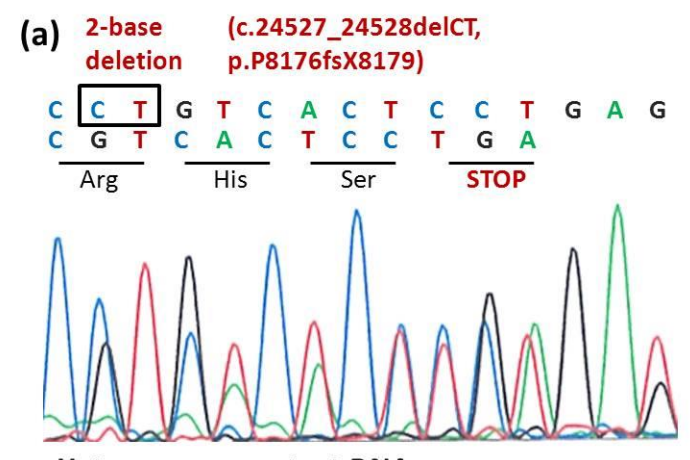

Heterozygous mutant DNA sequence

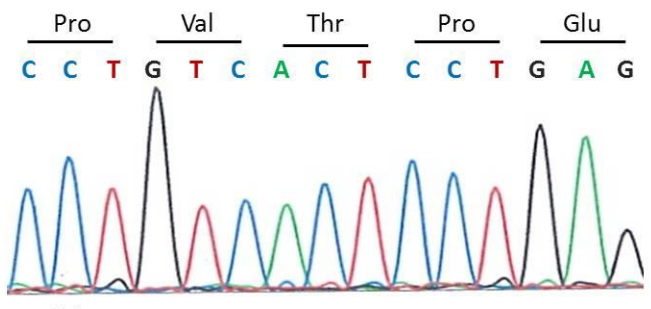

Wild type DNA sequence (b) 4-base (c.24250_24253dupGTCA, duplication p.T8085fs X8100)

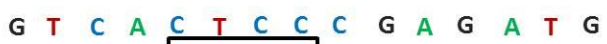

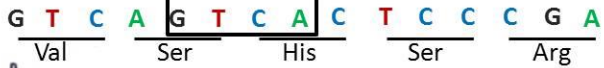

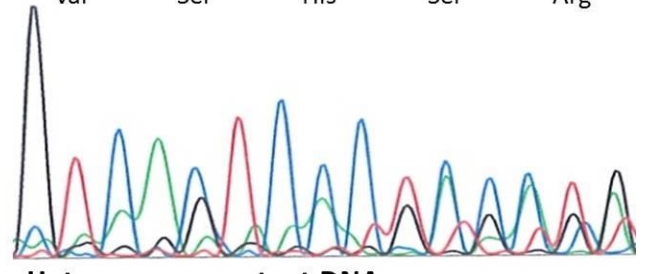

Heterozygous mutant DNA sequence

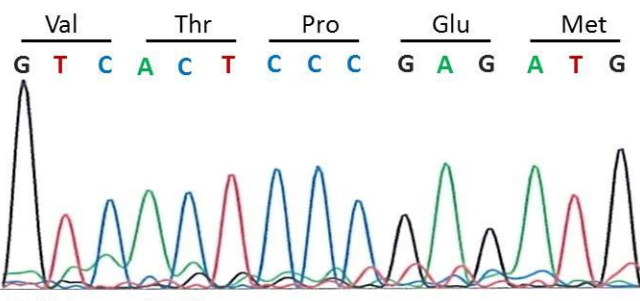

Wild type DNA sequence

Figure 9. Identification of two heterozygous mutations - one deletion and one duplication - in the $N E B$ gene.

Further testing of the parents revealed that the father carries the deletion and the mother has the heterozygous duplication (Figure 10.). One of the two sisters of the patient carries wild type alleles, while another sister and the brother are heterozygous for the duplication (Figure 10.). Thus, the clinically unaffected family members carry either wild type alleles or only one of the mutant alleles; 
either the duplication or the deletion. The patient however is a compound heterozygous carrier of both mutations.
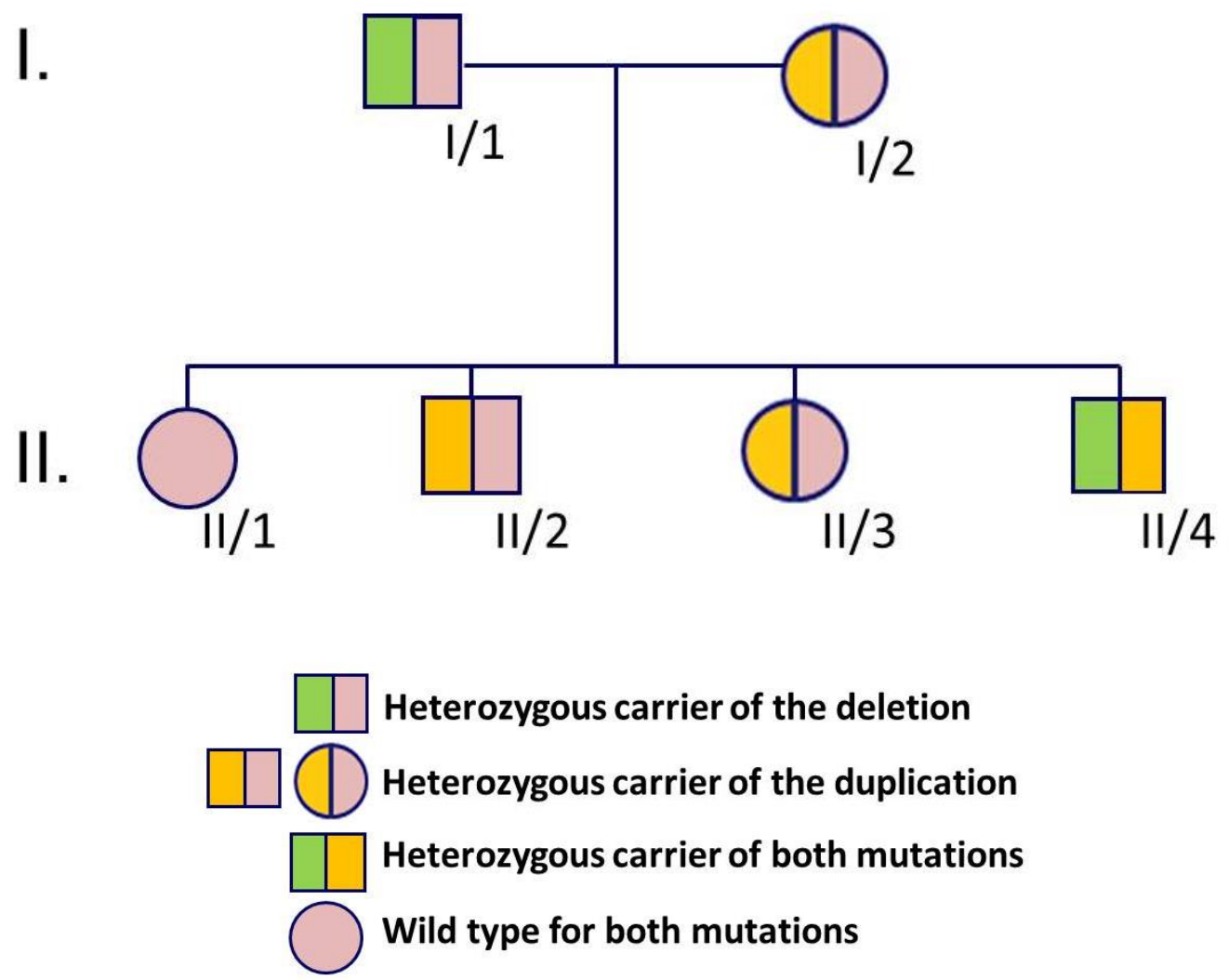

Figure 10. Genetic screening of the affected family. The patient (II/4) and his clinically unaffected father (I/1) carry the deletion in heterozygous form, while the other unaffected family members (I/2, II/1, II/2, II/3) carry the wild type allele. The patient (II/4) and his clinically unaffected mother (I/2), brother (II/2) and sister (II/3) carry the duplication in heterozygous form, while the other unaffected family members (I/1, II/1) carry the wild type allele. These results suggest that the deletion is of paternal origin and the duplication is of maternal origin.

\subsubsection{Post-test counselling in nemaline myopathy}

During the post-test genetic counselling, the parents were informed about their carrier status. In details, the performed investigations proved the presence of both previously identified mutation in the affected child and revealed that the 
deletion has paternal and the duplication has maternal origin. The performed investigations also revealed that two of the clinically unaffected siblings are also carrier of the maternal duplication and none of the clinically unaffected siblings are carrier of the paternal deletion.

These results had high impact on family planning, since they suggested autosomal recessive inheritance of the disease and proved that there is a $25 \%$ chance of expecting an affected child from the $5^{\text {th }}$ pregnancy of the mother.

Based on the above findings, chorion villus sampling, fetal DNA isolation and fetal genetic testing were offered for the pregnant mother to detect the two investigated mutations of the $N E B$ gene and to ensure the delivery of a healthy newborn. However, after detailed discussion with the genetic counsellor and with the family members and other relatives, the mother did not chose to undergo prenatal genetic testing, but referring to social causes she requested the termination of pregnancy before the $12^{\text {th }}$ gestational week.

\subsection{Results in hereditary hyperekplexia}

\subsubsection{Pre-test counselling in hereditary hyperekplexia}

A 27 -year-old pregnant woman on the $10^{\text {th }}$ gestational week arrived for genetic counselling to assess recurrence risk of hereditary hyperekplexia and discuss prenatal genetic testing possibilities. She reported on her second child who suffers from hereditary hyperekplexia. Genetic testing was not performed previously.

During pre-test genetic counselling the purposes of the genetic studies were set and were the followings: To identify the causative abnormality of hereditary hyperekplexia in the affected child, to determine inheritance and recurrence risk with the identification of the possible paternal origin of the alteration and to provide the option of the prenatal diagnostic testing for the pregnant mother. The mother was also informed about the method of the genetic investigation and about the time it requires. 
Besides these details, the mother was also informed about the legal regulations on the genetic investigations. After discussing this topic with the whole family, both parents gave their written informed consents and the genetic investigations were initiated.

\subsubsection{Genetic investigation revealed heterozygous missense mutation}

The most common form of hereditary hyperekplexia develops as the consequence of mutations in the GLRA1 gene. Therefore, direct sequencing of the coding regions and the flanking introns of the GLRAl gene was performed and revealed a novel heterozygous missense mutation (c.211A/T, p.Ile71Phe) in exon 3 (Figure 11.).

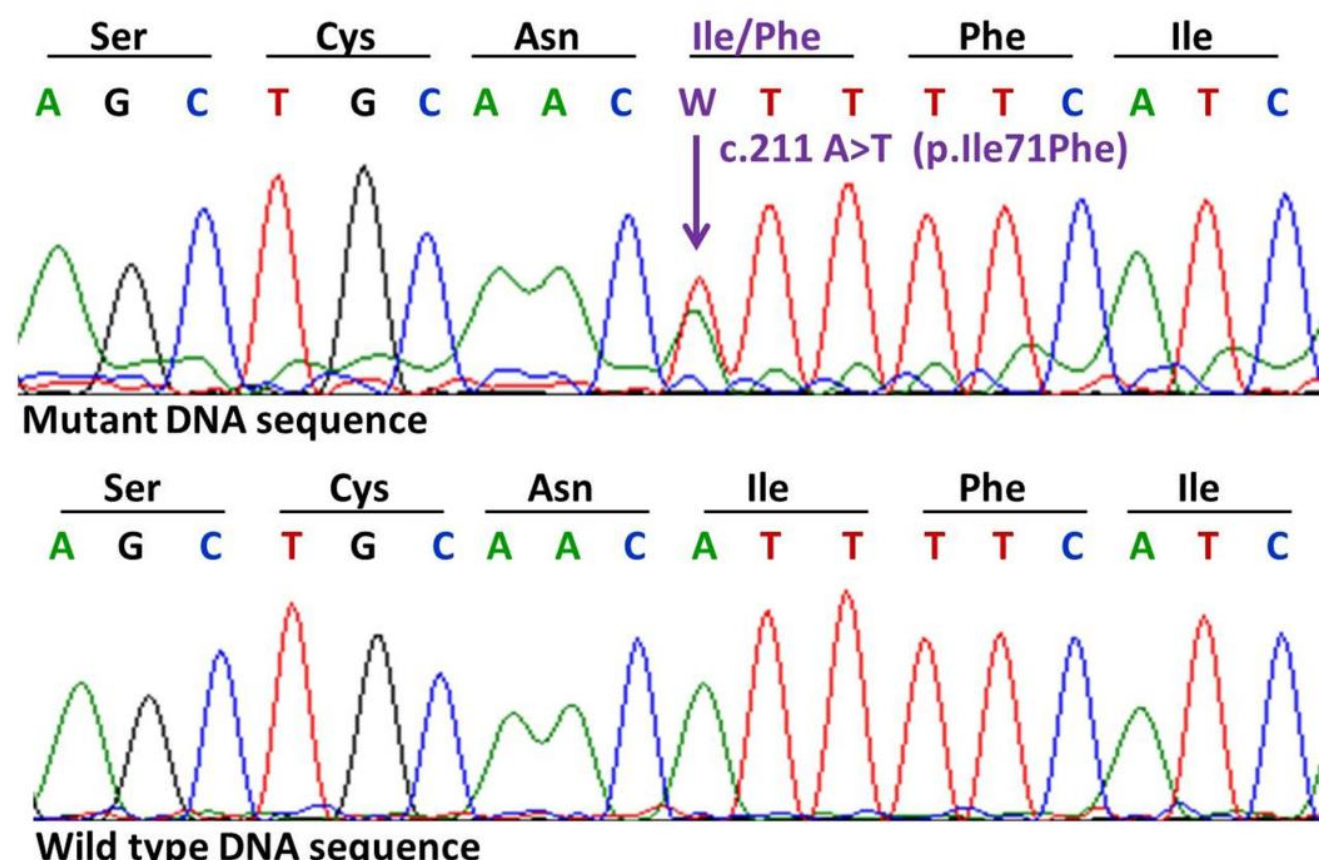

Figure 11. Identification of a novel heterozygous missense mutation of the GLRAI gene.

Comparison of GLRA1 protein sequences in the region of the mutation (p.Ile71Phe) from different species indicates that the region is highly conserved (Figure 12.). 
Homo sapiens

Pan troglodytes

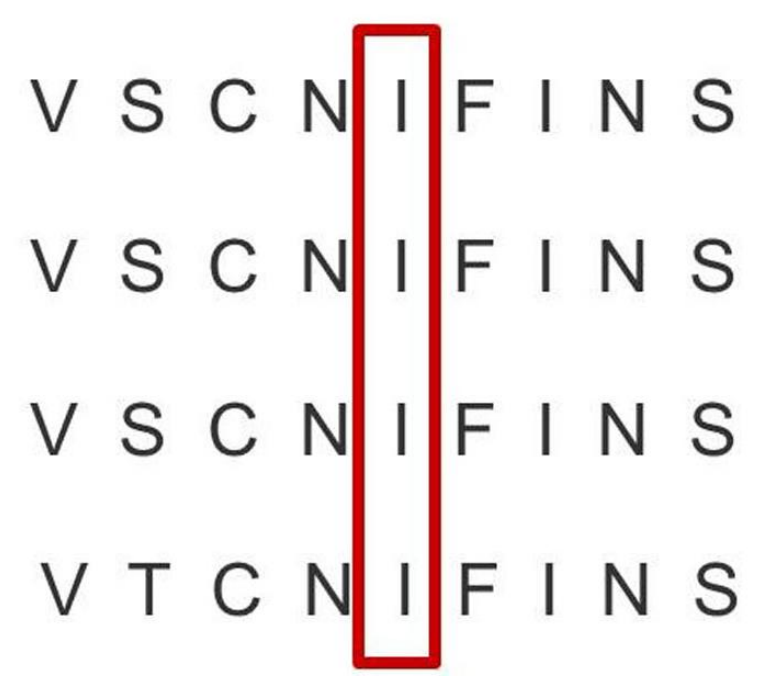

Figure 12. Conservation of the region of the mutation throughout the evolution.

Genetic screening of the affected family revealed that the clinically unaffected parents (I/1 and I/2) and the unaffected sister (II/1) did not carry the mutation, suggesting that the identified novel sequence alteration is a de novo mutation in the patient.

\subsubsection{Post-test counselling in hereditary hyperekplexia}

During the post-test genetic counseling, the parents were informed about the identified novel heterozygous de novo missense mutation in the affected child. It was emphasized that the parents did not carry the identified mutation therefore the risk of disease recurrence is very low and correlate with the risk of new mutation appearance rate. Based on the results prenatal diagnostic testing for hereditary hyperekplexia is not required. The results of the performed genetic testing suggest autosomal dominant inheritance, which will be an important issue when the affected child will grow up and will decide family planning. 


\section{Discussion}

\subsection{Angelman syndrome caused by paternal isochromosome 15q UPD}

In this study the case of a 16-month-old Hungarian boy affected by delayed psychomotor development and dysmorphic features is reported. Cytological and molecular genetic investigation revealed UPD suggesting a Robertsonian-like translocation 45,XY,der(15;15)(q10;q10). A similar balanced 15;15 translocation resulting from paternal UPD in a child with Angelman syndrome was reported by Freeman et al. (1993). Results from polymorphic marker analysis for the fibrillin-1 gene, located in 15q21.1, indicated that both arms of the aberrant chromosome 15 were inherited from the father, allowing the diagnosis of Angelman syndrome caused by paternal UPD. DNA polymorphic markers demonstrated that the patient was homozygous at all loci for which the father was heterozygous, suggesting that the structural rearrangement was an isochromosome $15 q$ and not a Robertsonian translocation.

The severity of Angelman syndrome varies significantly. The mildest symptoms have been reported for mutations of the UBE3A gene, whereas the most severe symptoms are reported for large deletions on chromosome 15 (Bottani et al., 1994; Tonk et al., 1996; Smith et al., 1997; Prasad et al., 1997; Moncla et al., 1999). Previous studies suggested that patients with Angelman syndrome caused by UPD may remain undiagnosed because of their milder or less typical phenotype, leading to an overall under-diagnosis of the disease (Lossie et al., 2001; Varela et al., 2004). In the investigated patient, we observed dysmorphic features, developmental delay, speech impairment and sleep disturbances, excessive mouthing behavior, short attention span, hand flapping, fascinating with water, and characteristic EEG and MRI results. The clinical features of our patient are similar to previously published results (Table 6.). The symptoms of the patient are relatively mild, which correlates well with the previous observations that Angelman syndrome patients with UPD usually have less severe clinical symptoms (Table 6.) 


\begin{tabular}{|c|c|c|}
\hline $\begin{array}{c}\text { The analyzed parameters } \\
\text { at diagnosis }\end{array}$ & $\begin{array}{l}\text { Values for the } \\
\text { Hungarian patient with } \\
\text { Angelman syndrome }\end{array}$ & $\begin{array}{c}\text { Values for } 13 \text { patients } \\
\text { with Angelman } \\
\text { syndrome }\end{array}$ \\
\hline \multicolumn{3}{|l|}{ Age (months) at diagnosis } \\
\hline $0-24$ & 1 & 0 \\
\hline $25-36$ & - & 5 \\
\hline $37-60$ & - & 8 \\
\hline Gender & M & $8 \mathrm{M} / 5 \mathrm{~F}$ \\
\hline Short attention span & + & $12 / 13(92 \%)$ \\
\hline History of sleep difficulties & + & $12 / 13(92 \%)$ \\
\hline Normal tone at evaluation & + & $12 / 13(92 \%)$ \\
\hline Mouthing behavior & + & $11 / 13(85 \%)$ \\
\hline Hand flapping & + & $11 / 13(85 \%)$ \\
\hline Drooling & + & $10 / 13(77 \%)$ \\
\hline Feeding difficulties in infancy & - & $10 / 13(77 \%)$ \\
\hline Ataxic or broad based gait & - & $8 / 11(73 \%)$ \\
\hline Gastro-esophageal reflux & - & $9 / 13(69 \%)$ \\
\hline Widely spaced teeth & + & $9 / 13(69 \%)$ \\
\hline Fascination with water & + & $8 / 13(62 \%)$ \\
\hline Easily provoked laughter & + & $8 / 13(62 \%)$ \\
\hline Clinical seizures & - & $6 / 13(46 \%)$ \\
\hline $\mathrm{BMI}>85 \%$ & + & $6 / 13(46 \%)$ \\
\hline Unusually light hair or skin color & - & $3 / 13(23 \%)$ \\
\hline Prognathism & - & $3 / 13(23 \%)$ \\
\hline Mid-face hypoplasia & - & $2 / 13(15 \%)$ \\
\hline
\end{tabular}

Table 6. The clinical features of the Hungarian patient compared to the 13 patients with UPD/imprinting defects summarized by Tan et al. (2011). 
The patient was diagnosed with Angelman syndrome at the age of 16 months, earlier than in previous reports of UPD, allowing the parents to be given a correct prognosis and an explanation of delayed neurological developmental as well as the possibility of early interventional therapy. In addition, the parents were counselled that the child is at risk for obesity and its associated complications, which could be managed with lifestyle adjustments. As the aberration was the result of a de novo occurrence, the parents were not counselled on the risk of recurrence for further pregnancies.

\subsection{Nemaline myopathy type 2 caused by compound heterozygous mutations with parental origin}

Nemaline myopathies are a clinically and molecularly heterogeneous group of congenital myopathies (Wallgren-Pettersson et al., 2011; Nance et al., 2012). The combination of characteristic clinical and histopathologic features are diagnostic for the disorder in most cases (North et al., 2011). The presence of red inclusions detected with Gomori trichrome staining and of rod-shaped particles in toluidine blue stained tissue from the patient strongly suggest nemaline myopathy (Wallgren-Pettersson et al., 2011; Nance et al., 2012). Ultrastructural studies reveal nemaline bodies as electron-dense, rod-shaped structures appearing as thickened Z-disks (Wallgren-Pettersson et al., 2011; Nance et al., 2012). Muscle imaging by MR can be helpful to visualize the pattern of selective muscle involvement and guide in localizing the site of the biopsy (Fischer et al., 2006; Mercuri et al., 2007).

The work up of a case with nemaline myopathy is further complicated by its heterogeneous genetic background: eight known causative genes have been linked to this condition and both autosomal dominant and recessive inheritance has been observed (Wallgren-Pettersson et al., 1999 and 2011). Six of these genes encode proteins associated with sarcomeric thin filaments (Wallgren-Pettersson et al., 1999 and 2011). Recessive mutations in the $N E B$ gene, located on chromosome 2q22-23 are the most commonly recognized cause of the disease 
(Labeit et al., 2011). This gene has 182 exons and missense, nonsense and frameshift mutations have been reported (Wallgren-Pettersson et al., 2002). Hotspots have not been found and many patients proved to be compound heterozygotes for two mutations within the gene (Wallgren-Pettersson et al., 2002). The nebulin protein has a wide range of functions, including thin filament length specification and regulation of muscle contraction (Labeit et al., 2011).

The clinical, histological and molecular genetic findings in our patient are consistent with the typical congenital form of nemaline myopathy type 2 , caused by mutations in the $N E B$ gene (Wallgren-Pettersson et al., 2002). Compound heterozygosity for two novel mutations was found. A 2-base deletion (c.24527_24528delCT, p.P8176fsX8179) was inherited from the father and a 4base duplication (c.24250_24253dupGTCA, p.T8085fsX8100) from the mother. These novel mutations led to a translational frameshift and a premature termination codon in the respective translated sequences and thus, presumably, to truncated nebulin protein.

Nemaline myopathy is a debilitating condition and further research is warranted in order to explore the details of the molecular pathology of this disorder. These efforts are complicated by the heterogenic molecular background of the disease and the fact that certain genes encode very large proteins, like nebulin. Molecular diagnosis however becomes available for more and more patients supporting preimplantation or prenatal diagnosis for subsequent pregnancies. This case report extends the genetic profile of nemaline myopathy with two previously unreported mutations in the $N E B$ gene.

\subsection{Hereditary hyperekplexia caused by de novo missense mutation}

In this study, a Hungarian family with one affected patient with hereditary hyperekplexia, a potentially fatal neurological disorder characterized by pronounced startle responses, was investigated. Abnormal movements, stiffness and convulsions were first noted in the patient at day 4 post-term, which correlates well with the early-onset of the disease. The initial severe symptoms of the patient 
were attenuated by carbamazepine therapy and physiotherapy and subsequently diminished with age.

Hereditary hyperekplexia has been linked to genetic alterations in genes involved in an inhibitory neurotransmitter, glycine neurotransmission (Harvey et al., 2008; James et al., 2012). GLRA1 mutations account for approximately $30 \%$ of all cases with hereditary hyperekplexia (Rees et al., 1994). Both compound heterozygous patients and homozygous mutation carriers have been described in the literature for recessive forms of the disease (Humeny et al., 2002). A heterozygous missense mutation (c.211A/T, p.Ile71Phe) was detected in the patient in exon 3 of the GLRA1 gene, establishing the diagnosis of hereditary hyperekplexia type 1 and suggesting that the mutation is an autosomal dominant form of the disease. As the non-coding regions of the GLRAl gene were not examined, we cannot exclude the possibility of second mutation that represents a recessive form in our patient.

The GLRAl gene encodes a neurotransmitter-gated ion channel transmembrane protein with three transmembrane segments (Lynch et al., 2004; Becker et al., 2006). Binding of glycine to its receptor increases the chloride conductance, produces hyperpolarization and, thus, the inhibition of neuronal firing (Lynch et al., 2004; Becker et al., 2006). Previous studies have attributed dominant forms of hereditary hyperekplexia type 1 to mutations within the porelining transmembrane segment (No.: 2) and adjacent regions, recessive forms to mutations within the other transmembrane segments (No.: 1 and 3), and the null allele of the GLRA1 gene to the deletion of exons 1-7 (Lynch et al., 2004; Becker et al., 2006).

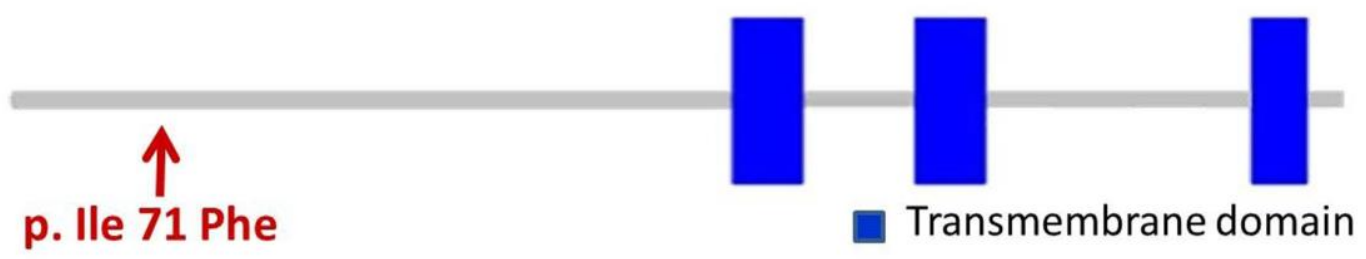

Figure 13. Location of the novel missense mutation on the GLRA1 protein. 
The novel heterozygous missense mutation (p.Ile71Phe) reported here is located close to the $\mathrm{NH}_{2}$-terminal of the GLRA1 protein outside the transmembrane segments (Figure 13), in a highly conserved region (Figure 12). The mutation is located in a region that is not predicted or known to be a functional domain of the GLRA1 protein. Other missense mutations have been detected in this region in patients with hereditary hyperekplexia type 1 (p.Trp68Cys and p.Arg72His; Harvey et al., 2008), and in spasmodic mouse (p.Ala52Ser; Saul et al., 1994). The functional analysis performed on the spasmodic mouse model suggested that the p.Ala52Ser missense mutation results in reduced glycine sensitivity (Saul et al., 1994). Based on these previous studies, we hypothesize that the reported novel missense mutation detected in our Hungarian patient might lead to reduced glycine sensitivity as well.

It is also interesting to note, that previously reported missense mutations in this region (human p.Trp68Cys and p.Arg72His and murine p.Ala52Ser) are all associated with the recessive form of hereditary hyperekplexia type 1, indicating the possibility that other undetected mutations might contribute to the clinical symptoms of our Hungarian patient.

Having identified the putative causative mutation in the affected patient, clinically unaffected family members were also screened and shown to carry only wildtype sequence of the GLRAl gene. Our results suggest that this novel missense sequence change (c.211A/T, p.Ile71Phe) identified in the affected patient is a de novo mutation. Our results correlate well with the data of the literature indicating that approximately $70 \%$ of the disease-causing GLRA1 mutations rise de novo (Kang et al., 2008).

The consequences of the hereditary hyperekplexia type 1 can be severe, warranting further efforts to elucidate the nature of the disease despite the complications implicit with the heterogenic genetic background. With the identification of the underlying genetic abnormalities, prenatal screening is available for affected families and allows informed family planning. In the future, knowledge of the genetic causes of this life-threatening disease may also contribute to the development of novel therapeutic alternatives. 


\subsection{Difficulties of genetic counselling in neurogenetic disorders}

Genetic counselling is primarily dependent upon precise diagnosis and upon accurate pedigree. The genetic counsellor always need to be careful with the diagnosis even if there is a clinical suspicion of certain diseases, the counsellor has to re-assess the symptoms of the affected patients, consider the appearance of the disease throughout the generations and determine the possible manners of inheritance.

This accuracy of the counsellor is shown in the presented first case with Angelman syndrome, since the correct genetic diagnosis was established at the age of 16 months. To my knowledge, this is earliest diagnosed Angelman syndrome compared to previous reports of UPD (Table 6.), allowing the parents to be given a correct prognosis and an explanation of delayed neurological developmental as well as the possibility of early interventional therapy. In addition, the parents were counseled that the child is at risk for obesity and its associated complications, which could be managed with lifestyle adjustments. As the aberration was the result of a de novo occurrence, the parents were not counseled on the risk of recurrence for further pregnancies.

Even if the diagnosis can suggest a group of monogenic neurogenetic diseases, which occurred in the case of nemaline myopathy establishing the accurate genetic diagnosis is still difficult. Since mutations in several genes can lead to the same phenotype such as the mutations of the following genes TPM3, NEB, ACTA1, TPM2 ,TNNT, CFL, KBTBD13, and KLHL40 can lead to the development of nemaline myopathy. In this case, after screening several genes, the causative compound heterozygous mutations were finally found in the $N E B$ gene suggesting nemaline myopathy type 2. After the causative mutations were identified, investigation of the whole family helped to assess carrier statuses and the recurrence risk of the disease.

Sometimes the identification of the putative causative mutation and establishing the correct genetic diagnosis are not enough for determining the mode 
of inheritance and the recurrence risk of the diasease. This was the case with the Hungarian family having a child affected by hereditary hyperekplexia. With the identification of the novel missense heterozygous mutation of the GLRA1 gene, the established genetic diagnosis was hereditary hyperekplexia type 1. However, this type of the disease can have autosomal dominant or recessive inheritance as well. In case of a homozygous mutation the recessive inheritance is clear. In case of a heterozygous mutation the dominant inheritance can only be supposed, since there is a chance of an unidentified second mutation in the uninvestigated, non-coding regions of the GLRA1 gene.

The development of new techniques for antenatal and prenatal diagnosis of chromosomal anomalies, monogenic or multifactorial disorders and an increased ability to recognize carriers of recessive genes greatly improve the quality of genetic diagnosis. The Human Genome Project also helped the discoveries of candidate genes and novel gene variations in the background of monogenic diseases such as neurogenic disorders. There is still a strong need of further developments, since several neurogenic disorders have no causative therapy. Hopefully in the future genetic counselling will not only help family planning, but also the initiation of personalized therapy.

Another important aspect of genetic counselling is empathy of the counsellor. In counselling, simple statements of risk are rarely sufficient. Clinical acumen is required to perceive the unspoken fears and feelings of guilt, which are usually associated with inherited disease. Sometimes it is really difficult to eliminate unwanted and un-appropriate feelings of the parents. In the family affected by nemaline myopathy type 2 , the mother was pregnant at the time of the genetic counselling and investigations. Even though, the performed investigations elucidated the carrier statuses of the parents, accurately determined the recurrence risk (25\%) and provide the possibility of prenatal screening, the family decided to terminate the pregnancy and not to undergo chorionic villus sampling and prenatal screening. Behind this decision, there are several rational reason and spoken and unspoken feelings. As a genetic counsellor, I can help the individual or the family with accurate and detailed informations about the disease, prognosis, outcomes, 
therapeutic modalities and family planning, but all the counsellors must accept that the final decision is made by the patient or the family.

\subsection{The future prospect of genetic investigations in neurogenetic disorders}

Although multifactorial diseases are more common than monogenic disorders, studies of the latter ones provide an invaluable opportunity to learn about underlying molecular mechanisms, thereby contributing a great deal to our understanding of all forms of genetic disease (Antonarakis \& Beckmann, 2006).

Before the human genome was sequenced, researchers relied on laborintensive, slow-going techniques for mapping and isolating disease-associated genes. For instance, although efforts to isolate the gene associated with Huntington's disease began in the late 1970s, the gene was not identified until 1993. The Human Genom Project has mapped polymorphisms along the length of every human chromosome and has made this information freely available to scientists worldwide (www.hapmap.org). These polymorphic markers can be used to map disease-associated genes.

In this study, polymorphic markers were used to perform segregational analysis of chromosome 15 in a family affected by Angelman syndrome. The performed genetic investigations demonstrated that the paternal origin of chromosome 15 in the affected child and confirmed the clinical suspect of Angelman syndrome.

Due to the accelerated discoveries made in the last two decades, there are a wide range and huge amount of genetic and genomic findings available from previous studies conducted worldwide recently. In order to use these discoveries efficiently and make them available for the researchers worldwide, bioinformatics has also showed a great improvement.

There are several examples in everyday use of bioinformatics in the investigation of neurogenic disorders: In this study, the neurogenic disorders were searched in the database of Online Mendelian Inheritance in Man (OMIM), which 
is a regularly updated, online database established in 1997 by Dr. Victor A. McKusick and is focused on inherited genetic diseases in humans (www.omim.org). After the genetic investigations were performed, the obtained sequencing data was compared to the ones in the Ensemble Genome Browser (www.ensemble.org) and was screened for diseases causing variations. Possible impacts of genetic variations were checked by using PolyPhen-2 (http://genetics.bwh.harvard.edu/pph2/).

These recent improvements demonstrate that the field of neurogenetics develops rapidly, which means that the genetic counsellor needs to be always update and keep up with the developments of this field. Since neurogenetics is now in the focus of research of several groups worldwide, hopefully the forthcoming future developments will not only elucidate the disease-causing genetic abnormalities of neurogenetic disrorders, but will provide a solid basis for the development of novel therapeutic modalities for the affected patients. 


\section{Summary}

In this study, my aim was to summarize the genetic investigations and the difficulties of the genetic counselling on family planning in Hungarian families affected by three different neurogenetic disorders such as Angelman syndrome, nemaline myopathy and hereditary hyperekplexia.

Angelman syndrome is a rare neurogenetic disorder that results in intellectual and developmental disturbances, seizures, jerky movements and frequent smiling. Angelman syndrome is caused by two genetic disturbances: genes on the maternally inherited chromosome 15 are deleted or inactivated or two paternal copies of the corresponding genes are inherited. The results of this study allowed the earliest reported diagnosis of Angelman syndrome in a 16-month-old child with clinical symptoms. The patient was referred with minor facial anomalies, neurodevelopmental delay and speech impairment. Cytogenetic results suggested a de novo Robertsonian-like translocation involving both $\mathrm{q}$ arms of chromosome 15: 45,XY,der(15;15)(q10;q10). Molecular genetic studies with polymorphic markers of the fibrillin-1 gene, located in the $15 \mathrm{q} 21.1$, revealed that both arms of the translocated chromosome were derived from a single paternal chromosome 15 (isodisomy) and led to the diagnosis of Angelman syndrome caused by UPD. Angelman syndrome resulting from UPD caused by de novo balanced translocation $\mathrm{t}(15 \mathrm{q} ; 15 \mathrm{q})$ of a single paternal chromosome has been reported by other groups. The detection of this rare UPD cause of Angelman syndrome contributes to the deeper understanding of the phenotype-genotype correlation in Angelman syndrome for non-deletion subclasses.

Nemaline myopathy is a type of the heterogeneous group of congenital myopathies. Generalized hypotonia, weakness and delayed motor development are the main clinical features of the typical congenital form. Histopathology shows characteristic nemaline rods in the muscle biopsy. Mutations in at least seven genes proved to be responsible for this muscle disease. Here I have investigated a Hungarian family with a child affected by nemaline myopathy type 2 caused by compound heterozygosity for two novel mutations, a deletion and a duplication in 
the $N E B$ gene. The deletion was inherited from the father and the duplication from the mother. Since nemaline myopathy is a debilitating condition, further research is warranted in order to explore the details of the molecular pathology of this disorder. These efforts are complicated by the heterogenic molecular background of the disease. Molecular diagnosis however becomes available for more and more patients supporting preimplantation or prenatal diagnosis for subsequent pregnancies. Here I report extends the genetic profile of nemaline myopathy with two previously unreported mutations in the $N E B$ gene.

Hereditary hyperekplexia is a neurological disorder characterized by excessive startle responses with violent jerking to noise or touch, stiffening of the trunk and limbs, clenching fists and attacks of a high-frequency trembling. Hereditary hyperekplexia has a heterogeneous genetic background with several identified causative genes and demonstrates both dominant and recessive inheritance. Mutations in the GLRA1 gene occur in about $30 \%$ of the cases. In this study, I report a Hungarian pedigree with one affected boy whose abnormal movements, muscle stiffness and convulsions were first noted when he was 4 days old. Neurological and electrophysiological investigation suggested the clinical diagnosis of hereditary hyperekplexia. Direct sequencing of the coding regions and the flanking introns of the GLRAl gene revealed a novel heterozygous missense mutation (c.211A/T, p.Ile71Phe). Genetic screening of the patient's family revealed that the clinically unaffected parents and sister do not carry the mutation suggesting that the identified sequence change is a de novo mutation. Since hereditary hyperekplexia can have severe consequences, including sudden infant death due to laryngospasm and cardiorespiratory failure, identification of the causative genetic alteration(s) of the disease is high priority. Such knowledge is necessary for prenatal diagnosis, which would allow informed family planning and greater parental sensitivity to hereditary hyperekplexia-associated risks.

My investigations have great importance for the affected families since they help family planning. Hopefully, these findings might also provide the basis of future studies for the development of novel therapeutic modalities in neurogenetic disorders. 


\section{Acknowledgements}

I would like to thank to Prof. Dr. Márta Széll and to Dr. Nikoletta Nagy their great supervising activity and support in performing this study in the cytogenetic and molecular laboratories of the Department of Medical Genetics Institute, University of Szeged. Thanks for all the colleagues of the Department of Medical Genetics Institute for their help in the administrative works with the patients and in carry out the cytogenetic and genetic diagnostic methods and investigations.

Special thanks to Prof. Dr. László Sztriha for his excellent neurogenetist and added great suggestions to my work and to Dr. Anna Gajda, who took part in the clinical part of the workup of the patient with nemaline myopathy type 2 .

Special thanks to Dr. Emöke Endreffy for the collaboration on the segregation analysis of chromosome 15 in case of the family having a child affected by Angelman syndrome.

Special thanks to Prof. Dr. Herczegfalvi Ágnes for the clinical part of the workup of the patient with hyperekplexia.

I am grateful to all the patients and the control individuals participated in this study. 


\section{Electronic database information}

Ensemble Genome Browser, (for the wild type sequencing data of the human genome, for the gene variation database regarding disease-causing and noncausing alterations and for the taxonomy analysis of the identified mutation on the GLRA1 gene). www.ensemble.org

Human Genom Project, (for the polymorphic markers and gene variation database). www.hapmap.org

Online Mendelian Inheritance in Man, (for the detailed informations on the genetics, inheritance, clinical features and identified mutations in monogenic neurogenetic disorders). www.omim.org

Polyphen-2, (for the prediction of the impact of a single nucleotide gene variation). http://genetics.bwh.harvard.edu/pph2/

UCSC Genome Bioinformatics, (for the design of specific primers used to amplify the sequenced regions of the genes). http://genome.ucsc.edu/ 


\section{References}

Al-Owain M, Colak D, Al-Bakheet A, Al-Hashmi N, Shuaib T, Al-Hemidan A, Aldhalaan H, Rahbeeni Z, Al-Sayed M, Al-Younes B, Ozand P, Kaya N. Novel mutation in GLRB in a large family with hereditary hyperekplexia. Clin Genet 2012;81:479-484.

Antonarakis SE, Beckmann JS. Mendelian disorders deserve more attention. Nat Rev Genet 2006;7:277-282.

Becker K, Hohoff C, Schmitt B, Christen HJ, Neubauer BA, Sandrieser T, Becker CM. Identification of the microdeletion breakpoint in a GLRA1null allele of Turkish hyperekplexia patients. Hum Mutat 2006;27:1061-1062.

Benzer S. Behavioral mutants of Drosophila isolated by countercurrent distribution. Proc Natl Acad Sci U S A 1967 Sep;58(3):1112-9.

Bottani A, Robinson WP, DeLozier-Blanchet CD, Engel E, Morris MA, Schmitt B, Thun-Hohenstein L, Schinzel A. Angelman syndrome due to paternal uniparentaldisomy of chromosome 15; milder phenotype? Am J Med Genet 1994;51:3540 .

Clayton-Smith J, Laan L. Angelman syndrome: a review of the clinical and genetic aspects. J Med Genet 2003;40:87-95.

Fischer D, Herasse M, Ferreiro A, Barragán-Campos HM, Chiras J, Viollet L, Maugenre S, Leroy JP, Monnier N, Lunardi J, Guicheney P, Fardeau M, Romero NB. Muscle imaging in dominant core myopathies linked or unlinked to the ryanodine receptor 1 gene. Neurology 2006;67:2217-2220.

Freeman SB, May KM, Pettay D, Fernhoff PM, Hassold TJ. Paternal uniparentaldisomy in a child with a balanced 15;15 translocation and Angelman syndrome. Am J Med Genet 1993;45:625-630.

Gajda A, Horváth E, Hortobágyi T, Gergev G, Szabó H, Farkas K, Nagy N, Széll M, Sztriha L. Nemaline Myopathy Type 2 (NEM2): Two Novel Mutations in the Nebulin (NEB) Gene. J Child Neurol 2013 Sep 20.

Gershon ES, Goldin LR. The outlook for linkage research in psychiatric disorders. J Psychiatr Res 1987;21:541-50.

Grenningloh G, Schmieden V, Schofield PR, Seeburg PH, Siddique T, Mohandas TK, Becker CM, Betz H. Alpha subunit variants of the human glycine receptor: primary structures, functional expression and chromosomal localization of the corresponding genes. EMBO J 1990;9:771-776. 
Harvey K, Duguid IC, Alldred MJ, Beatty SE, Ward H, Keep NH, Lingenfelter SE, Pearce BR, Lundgren J, Owen MJ, Smart TG, Luscher B, Rees MI, Harvey RJ. The GDP-GTP exchange factor collybistin: as essential determinant of neuronal gephyrin clustering. J Neurosci 2004;24:5816-5826.

Harvey RJ, Topf M, Harvey K, Rees MI. The genetics of hyperekplexia: more than startle! Trends Genet 2008;24:439-447.

Horváth E, Horváth Z, Isaszegi D, Gergev G, Nagy N, Szabó J, Sztriha L, Széll M, Endreffy E. Early detection of Angelman syndrome resulting from de novo paternal isodisomic 15q UPD and review of comparable cases. Mol Cytogenet 2013;8:35.

Humeny A, Bonk T, Becker K, Jafari-Boroujerdi M, Stephani U, Reuter K, Becker C-M. A novel recessive hyperekplexia allele GLRA1 (S231R): genotyping by MALDI-TOF mass spectrometry and functional characterisation as a determinant of cellular glycine receptor trafficking. Europ J Hum Genet 2002;10:188-196.

James VM, Gill JL, Topf M, Harvey RJ. Molecular mechanisms of glycine transporter GlyT2 mutations in startle disease. Biol Chem 2012;393:283-289.

Johnston JJ, Kelley RI, Crawford TO, Morton DH, Agarwala R, Koch T, Schäffer AA, Francomano CA, Biesecker LG. A novel nemaline myopathy in the Amish caused by a mutation in troponin T1. Am J Hum Genet 2000;67:814-821.

Judge DP, Biery NJ, Dietz HC. Characterization of microsatellite markers flanking FBN1: utility in the diagnostic evaluation for Marfan syndrome. Am J Med Genet 2001;99:39-47.

Kang HC, Jeong You S, Jae Chey M, Sam Baik J, Kim JW, Ki CS. Identification of a de novo Lys304Gln mutation in the glycine receptor alpha-1 subunit gene in a Korean infant with hyperekplexia. Mov Disord 2008;23:610-613.

Kirstein L, Silfverskiold BP. A family with emotionally precipitated 'drop seizures'. Acta Psychiat Neurol Scand 1958;33:471-476.

Konopka RJ, Benzer S. Clock mutants of Drosophila melanogaster. Proc Natl Acad Sci U S A 1971;68:2112-6.

Labeit S, Ottenheijm CA, Granzier H. Nebulin, a major player in muscle health and disease. FASEB J 2011;25:822-829.

Lapunzina P, Sánchez JM, Cabrera M, Moreno A, Delicado A, de Torres ML, Mori AM, Quero J, Lopez Pajares I. Hyperekplexia (startle disease): a novel mutation (S270T) in the M2 domain of the GLRA1 gene and a molecular review of the disorder. Mol Diagn 2003;7:125-128.

Lossie AC, Whitney MM, Amidon D. Distinct phenotypes distinguish the molecular classes of Angelman syndrome. J Med Genet 2001;38:834-845.

Lynch JW. Molecular structure and function of the glycine receptor chloride channel. Physiol Rev 2004;84:1051-1095. 
McElhinny AS, Schwach C, Valichnac M, Mount-Patrick S, Gregorio CC. Nebulin regulates the assembly and lengths of the thin filaments in striated muscle. J Cell Biol 2005;170:947-957.

Mercuri E, Pichiecchio A, Allsop J, Messina S, Pane M, Muntoni F. Muscle MRI in inherited neuromuscular disorders: past, present, and future. J Magn Reson Imaging 2007;25:433-440.

Moncla A, Malzac P, Voelckel MA, Auquier P, Girardot L, Mattei MG, Philip N, Mattei JF, Lalande M, Livet MO. Phenotype-genotype correlation in 20 deletion and nondeletion Angelman syndrome patients. EurJ Hum Genet 1999;7:131-139.

Nance JR, Dowling JJ, Gibbs EM, Bönnemann CG. Congenital myopathies: an update. Curr Neurol Neurosci Rep 2012;12:165-174.

North KN. Clinical approach to the diagnosis of congenital myopathies. Semin Pediatr Neurol 2011;18:216-220.

Petersen MB, Brøndum-Nielsen K, Hansen LK, Wulff K. Clinical, cytogenetic, and molecular diagnosis of Angelman syndrome: estimated prevalence rate in a Danish county; the disorder predominantly affects Anglo-Saxons. Am J Med Genet 1995;60:261262.

Poyatos D, Guitart M, Gabau E, Brun C, Mila M, Vaquerizo J, Coll MD. Severe phenotype in Angelman syndrome resulting from paternal isochromosome 15. J Med Genet 2002;39:e4

Prasad C, Wagstaff J. Genotype and phenotype in Angelman syndrome caused by paternal UPD 15. Am J Med Genet 1997;70:328-329.

Rees MI, Andrew M, Jawad S, Owen MJ. Evidence for recessive as well as dominant forms of startle disease (hyperekplexia) caused by mutations in the alpha-1 subunit of the inhibitory glycine receptor. Hum Molec Genet 1994;3:2175-2179.

Rees MI, Harvey K, Pearce BR, Chung S-K, Duguid IC, Thomas P, Beatty S, Graham GE, Armstrong L, Shiang R, Abbott KJ, Zuberi SM, Stephenson JBP, Owen MJ, Tijssen MAJ, van den Maagdenberg AMJM, Smart TG, Supplisson S, Harvey RJ. Mutations in the gene encoding GlyT2 (SLC6A5) define a presynaptic component of human startle disease. Nature Genet 2006;38: 801-806.

Reiss J, Gross-Hardt S, Christensen E, Schmidt P, Mendel RR, Schwarz G. A mutation in the gene for the neurotransmitter receptor-clustering protein gephyrin causes a novel form of molybdenum cofactor deficiency. Am J Hum Genet 2001;68:208-213.

Ryan SG, Dixon MJ, Nigro MA, Kelts KA, Markand ON, Terry JC, Shiang R, Wasmuth JJ, O'Connell P. Genetic and radiation hybrid mapping of the hyperekplexia region on chromosome 5q. Am J Hum Genet 1992;51:1334-1343.

Ryan MM, Ilkovski B, Strickland CD. Clinical course correlates poorly with muscle pathology in nemaline myopathy. Neurology 2003;60:665-673. 
Saul B, Schmieden V, Kling C, Mülhardt C, Gass P, Kuhse J, Becker CM. Point mutation of glycine receptor alpha 1 subunit in the spasmodic mouse affects agonist responses. FEBS Lett 1994;350:71-76.

Simon-Sanchez J, Singleton A. "Genome-wide association studies in neurological disorders". Lancet Neurol 2008;7:1067-1072.

Smith A, Marks R, Haan E, Dixon J, Trent RJ. Clinical features in 4 patients with Angelman syndrome resulting from paternal uniparental disomy. J Med Genet 1997;34:426-429.

Steffenburg S, Gillberg CL, Steffenburg U, Kyllerman M. Autism in Angelman syndrome: a population-based study. Pediatr Neurol 1996;14:131-136.

Tan W-H, Bacino CA, Skinner SA, Anselm I, Barbieri-Welge R, Bauer-Carlin A, Beaudet AL, Bichell TJ, Gentile JK, Glaze DG, Horowitz LT, Kothare SV, Lee HS, Nespeca MP, Peters SU, Sahoo T, Sarco D, Waisbren SE, Bird LM. Angelman Syndrome: Mutations Influence Features in Early Childhood. Am J Med Genet 2011;155:81-90.

Tanzi RE. "Genetic linkage studies of human neurodegenerative disorders". Curr Opin Neurobiol 1991;1:455-461.

Tonk V, Schultz RA, Christian SL, Kubota T, Ledbetter DH, Wilson GN. Robertsonian $(15 \mathrm{q}, 15 \mathrm{q})$ translocation in a child with Angelman syndrome: evidence of uniparental disomy. Am J Med Genet 1996;66:426-428.

Wallgren-Pettersson C, Sainio K, Salmi T. Electromyography in congenital nemaline myopathy. Muscle Nerve 1989;12:587-593.

Wallgren-Pettersson C, Pelin K, Hilpela P, Donner K, Porfirio B, Graziano C, Swoboda KJ, Fardeau M, Urtizberea JA, Muntoni F, Sewry C, Dubowitz V. Clinical and genetic heterogeneity in autosomal recessive nemaline myopathy. Neuromusc Disord 1999;9:564-572.

Wallgren-Pettersson C, Sewry CA, Nowak KJ, Laing NG. Nemaline myopathies. Semin Pediatr Neurol 2011;18:230-238.

Varela MC, Kok F, Otto PA, Koiffmann CP. Phenotypic variability in Angelman syndrome: comparison among different deletion classes and between deletion and UPD subjects. EurJ Hum Genet 2004;12:987-992.

Vercesi AM, Carvalho MR, Aguiar MJ, Pena SD. Prevalence of Prader-Willi and Angelman syndromes among mentally retarded boys in Brazil. J Med Genet 1999;36:498.

Williams CA, Beaudet AL, Clayton-Smith J, Knoll JH, Kyllerman M, Laan LA, Magenis RE, Moncla A, Schinzel AA, Summers JA, Wagstaff J. Angelman syndrome 2005: updated consensus for diagnostic criteria. Am J Med Genet 2006;140:413-418. 


\section{Abbreviations}

ACTA1: skeletal muscle $\alpha$-actin gene

AD: autosomal dominant inheritance

AR: autosomal recessive inheritance

ARHGEF9: postsynaptic glycine enhancer collybistin gene

CFL2: cofilin-2 gene

GLRA1: glycine receptor alpha 1 subunit gene

GLRB: glycine receptor beta subunit gene

GPHN: glycine receptor locator gephyrin gene

IBD: identity by descent

KBTBD13: kelch-repeat and BTB (POZ) domain containing 13

KLHL40: kelch-like family member 40

LOD: logarithm of odds

NEB: nebulin gene

OMIM: Online Mendelian Inheritance in Man

SLC6A5: glycine transporter solute carrier family 6 member 5 gene

STR: short tandem repeat

TPM2: $\beta$-tropomyosin gene

TPM3: $\alpha$-tropomyosin gene

TNNT1: muscle troponin T1 gene

UBE3A: ubiquitin protein ligase E3A

UPD: uniparental disomy

XR: X-linked recessive inheritance 
10. Appendix 


\title{
Early detection of Angelman syndrome resulting from de novo paternal isodisomic 15q UPD and review of comparable cases
}

\author{
Emese Horváth ${ }^{1 *}$, Zsuzsanna Horváth¹, Dóra Isaszegi ${ }^{1}$, Gyurgyinka Gergev², Nikoletta Nagy 1,3, János Szabó1, \\ László Sztriha², Márta Széll ${ }^{1,3}$ and Emőke Endreffy ${ }^{2}$
}

\begin{abstract}
Background: Angelman syndrome is a rare neurogenetic disorder that results in intellectual and developmental disturbances, seizures, jerky movements and frequent smiling. Angelman syndrome is caused by two genetic disturbances: either genes on the maternally inherited chromosome 15 are deleted or inactivated or two paternal copies of the corresponding genes are inherited (paternal uniparental disomy). A 16-month-old child was referred with minor facial anomalies, neurodevelopmental delay and speech impairment. The clinical symptoms suggested angelman syndrome. The aim of our study was to elucidate the genetic background of this case.

Results: This study reports the earliest diagnosed angelman syndrome in a 16-month-old Hungarian child. Cytogenetic results suggested a de novo Robertsonian-like translocation involving both q arms of chromosome 15: 45,XY,der(15;15)(q10;q10). Molecular genetic studies with polymorphic short tandem repeat markers of the fibrillin-1 gene, located in the 15q21.1, revealed that both arms of the translocated chromosome were derived from a single paternal chromosome 15 (isodisomy) and led to the diagnosis of angelman syndrome caused by paternal uniparental disomy.

Conclusions: AS resulting from paternal uniparental disomy caused by de novo balanced translocation t $(15 \mathrm{q} ; 15 \mathrm{q})$ of a single paternal chromosome has been reported by other groups. This paper reviews 19 previously published comparable cases of the literature. Our paper contributes to the deeper understanding of the phenotype-genotype correlation in angelman syndrome for non-deletion subclasses and suggests that patients with uniparental disomy have milder symptoms and higher BMI than the ones with other underlying genetic abnormalities.
\end{abstract}

Keywords: Angelman syndrome, Isodisomic 15, Uniparental disomy, Balanced translocation chromosome 15q

\section{Background}

Angelman syndrome (AS; OMIM 105830) is a rare neurodevelopmental disorder characterized by severe mental and physical delay, limited speech, fine tremor, ataxia, excessive mouthing behavior, fascination with water, jerky limb movements, seizures, craniofacial abnormalities and unusually happy sociable behavior characterized by frequent episodes of inappropriate smiling [1,2].

Seventy percent of AS cases investigated with molecular genetics methods are the result of a small deletion in the

\footnotetext{
* Correspondence: horvath.emese@med.u-szeged.hu

'Department of Medical Genetics, University of Szeged, 4 Somogyi B. utca,

H-6720, Szeged, Hungary

Full list of author information is available at the end of the article
}

11-13 region of the maternal chromosome 15. A deletion in the same region of the paternal chromosome 15 results in the sister disorder Prader-Willi syndrome (PWS). Expression of the genes in the 11-13 region is regulated by the PWS/AS imprinting center (IC), which differentially silences the paternal copy of the ubiquitin protein ligaseE3A $(U B E 3 A)$ gene in the hippocampus and in the cerebellum. Other genetic abnormalities resulting in AS reported include uniparental disomy (UPD; 5\%), mutations of the IC (5\%), mutations of the UBE3A gene (10\%), and other mechanisms (10\%) [3,4].

In this paper, we report a 16-month-old Hungarian child, who was referred to our genetic counseling unit with delayed psychomotor and speech development and

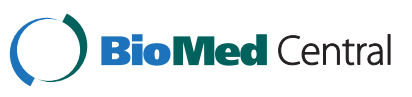


dysmorphic features, including wide nasal bridge, low set ears, thick lips, wide mouth with protuberant tongue (Figure 1). Tongue thrusts were observed. Head circumference was $47 \mathrm{~cm}$ (25 percentile). The affected child was born at term after an uneventful first pregnancy with normal weight (3260 g) and head circumference $(33 \mathrm{~cm})$. The Apgar scores were 9, 10 and 10 at 1, 5 and 10 minutes, respectively. No signs of decreased fetal movement, neonatal hypotonia or feeding difficulties were reported. The clinical phenotype of the patient suggested AS, therefore molecular cytogenetic investigations were carried out to elucidate the genetic background of the presented case.

\section{Results}

Cytogenetic analysis demonstrated a 45,XY,der(15;15) (q10;q10) karyotype in all analyzed cells from the index patient (III/1, Figure 2). All metaphase cells displayed 45 chromosomes, suggesting a balanced homologous rearrangement of the long arms of chromosomes 15 . The parent's karyotype was found to be normal, indicating a de novo chromosome rearrangement in the patient.

Analysis of polymorphic short tandem repeat (STR) markers of the fibrillin-1 gene, which is located in $15 \mathrm{q} 21.1$, revealed that both long arms of the aberrant chromosome 15 were inherited from the father (Figure 3), allowing a diagnosis of AS caused by paternal UPD. The patient was homozygous at all loci for which his father was heterozygous, indicating that the rearrangement resulted from an isodisomic 15q.

\section{Discussion}

Cytological and molecular genetic investigation revealed UPD suggesting a Robertsonian-like translocation 45,XY, $\operatorname{der}(15 ; 15)(\mathrm{q} 10 ; \mathrm{q} 10)$, a rearrangement of the acrocentric

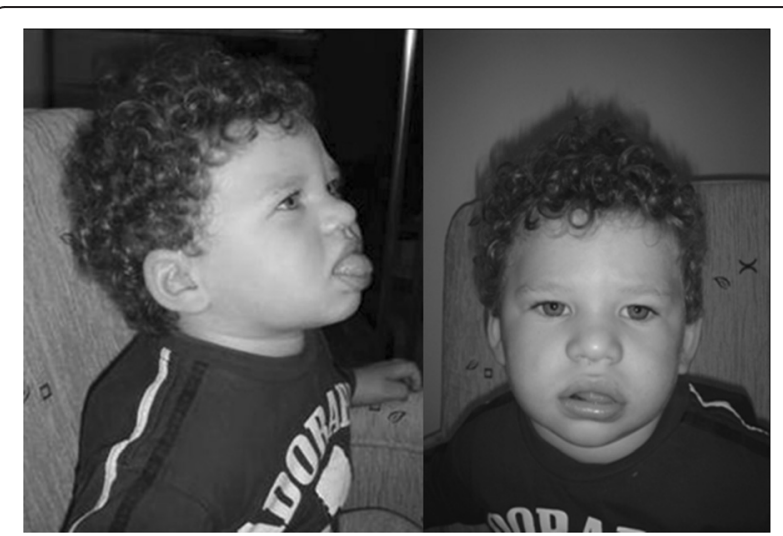

Figure 1 Clinical features of a patient with Angelman syndrome resulting from de novo paternal isochromosome 15q UPD. The dysmorphic symptoms of the 16 month old child include wide nasal bridge, low set ears, thick lips, wide mouth and protruding tongue. chromosomes. Robertsonian translocations mostly form de novo due to intrinsic properties of the acrocentric chromosomes, which are likely to be the results of the high homology between the short arm DNA sequences of them [5]. A similar balanced 15;15 translocation resulting from paternal UPD in AS were reported by Freeman et al. (1993) [6], by Tonk et al. (1996) [7], by Ramsden et al. (1996) [8], by Guitart et al. (1997) [9], by Fridman et al. (1998) [10] and by Robinson et al. (2000) [11].

Results from polymorphic STR marker analysis for the fibrillin-1 gene, located in 15q21.1, indicated that both arms of the aberrant chromosome 15 were inherited from the father, allowing a diagnosis of AS caused by paternal UPD. DNA polymorphic markers demonstrated that the patient was homozygous at all loci for which the father was heterozygous, suggesting that the structural rearrangement was an isodisomic $15 \mathrm{q}$ and not a Robertsonian translocation. Similar cases of AS resulting from isodisomic $15 \mathrm{q}$ associated UPD have already been demonstrated by Freeman et al. (1993) [6] and by Robinson et al. (2000) [11], however, the majority of the previously reported paternal UPD associated AS cases were heterodisomic [7-10].

The severity of AS symptoms varies significantly. Bottani et al. (1994) were the first, who reported that the phenotype of AS with paternal isochromosome 15 is milder than those caused by other mechanisms [12]. This observation was confirmed by Tonk et al. (1996) [7], Smith et al. (1997) [13], Fridman et al. (1998) [10] and Moncla et al. (1999) [14], however Prassad et al. (1997) [15] have not observed differences between deletion and UPD, moreover Poyatos et al. (2002) described an even more severe phenotype [3]. The mildest symptoms have been reported for mutations of the UBE3A gene $[2,12,14,16]$, whereas the most severe symptoms are reported for large deletions on chromosome 15 $[2,14,16]$. Varela et al. (2004) suggested that AS patients with UPD may remain undiagnosed because of their milder or less typical phenotype, leading to an overall under-diagnosis of the disease (Table 1) $[17,18]$. According to Tan et al. (2011) [4], 46\% of AS children with UPD/imprinting defect showed significantly higher body mass index (BMI) than the ones carrying deletions.

In the investigated patient, we observed dysmorphic features, developmental delay, speech impairment and sleep disturbances, excessive mouthing behavior, short attention span, hand flapping, fascinating with water, and characteristic EEG and MRI results. The clinical features of our patient are similar to previously published results $[4,7,9,12]$. The patient's AS symptoms are relatively mild, which correlates well with the previous observations that AS patients with UPD usually have less severe clinical symptoms $[8,10,11,13]$. The BMI of our patients was $>85 \%$, which correlated well with the previous results of Tan et al. 

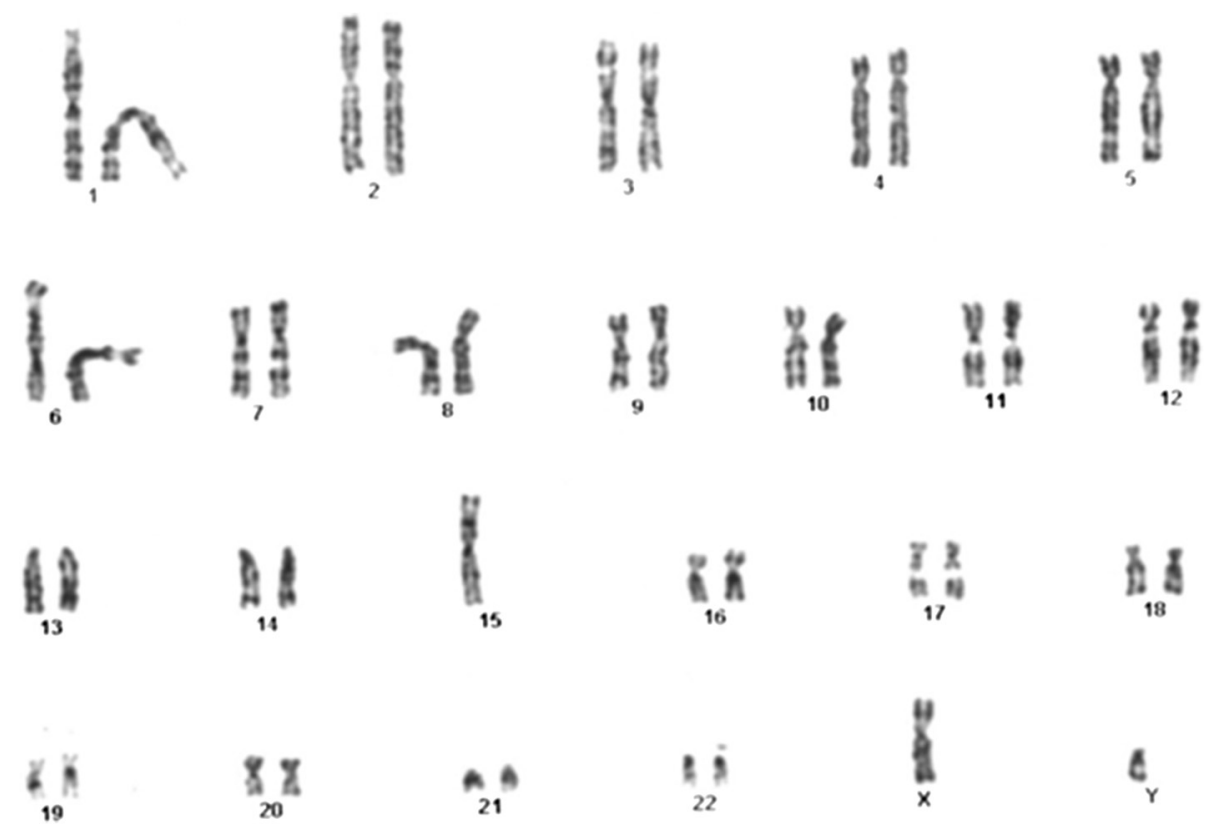

Figure 2 The karyotype of the AS patient. The cytogenetic image displays 45 metaphase chromosomes with an apparently balanced homologous rearrangement between the long arms of chromosomes 15. Cytogenetic result: 45,XY der(15;15)(q10;q10).

I.

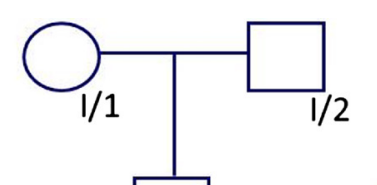

II.

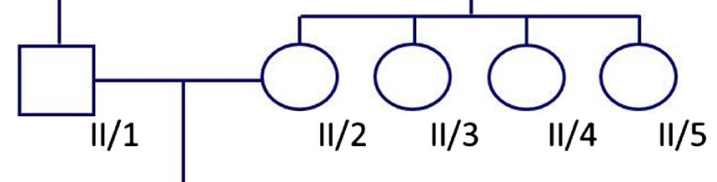

III.

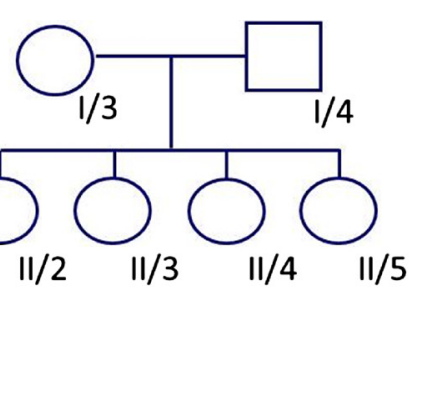

III/1

Marker:

MMTS2
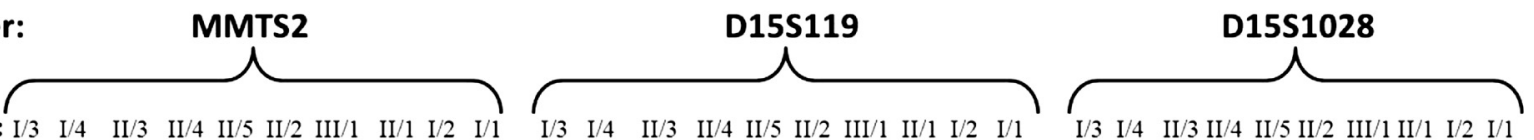

Patient: I/3 I/4 II/3 II/4 II/ 5 II $/ 2$ III/ 1 II $/ 1$ I/2 I/

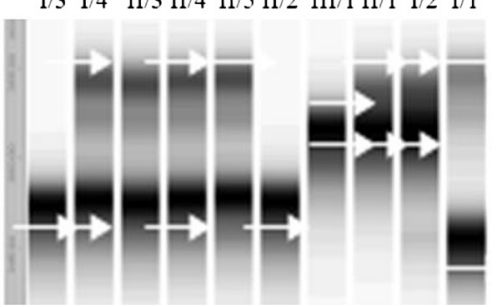

Figure 3 Genetic analysis of the affected family using polymorphic STR markers MMTS2, D15S119 and D15S1028 for the fibrillin-1 gene. Marker analysis of the patient (III/1), his parents (II/1, II/2), maternal aunts (II/3, II/4, II/5), maternal grandparents (I/3, I/4), and paternal grandparents $(1 / 1,1 / 2)$ was performed by ALFexpress gel electrophoresis. The patient is homozygous for polymorphisms occurring in the father but not the mother, indicating that both arms of the aberrant chromosome 15 were of paternal origin. 
Table 1 The clinical features of the patient, in order of frequency, compared to the 13 AS patients with UPD/ imprinting defects reported by Tan [4]

\begin{tabular}{ccc}
\hline $\begin{array}{c}\text { The analyzed } \\
\text { parameters at } \\
\text { diagnosis }\end{array}$ & $\begin{array}{c}\text { Values for the } \\
\text { patient described in } \\
\text { this report }\end{array}$ & $\begin{array}{c}\text { Values for the 13 AS } \\
\text { patients with UPD/ } \\
\text { imprinting defects } \\
\text { reported by Tan [4] }\end{array}$
\end{tabular}

Age (months) at

diagnosis

$\begin{array}{ccc}0-24 & 1 & 0 \\ 25-36 & - & 5 \\ 37-60 & - & 8 \\ \text { Gender } & M & 8 M / 5 F\end{array}$

Short attention span

History of sleep difficulties

Normal tone at evaluation

Mouthing

behavior

Hand flapping

Drooling

Feeding

difficulties in infancy

Ataxic or broad based gait

Gastro-esophageal

reflux

Widely spaced teeth

Fascination with water

Easily provoked laughter

Clinical seizures $\mathrm{BM} \mid>85 \%$

Unusually light

hair or skin color

Prognathism

Mid-face hypoplasia
$+$

12/13 (92\%)

$12 / 13(92 \%)$

12/13 (92\%)

11/13 (85\%)

11/13 (85\%)

10/13 (77\%)

10/13 (77\%)

8/11 (73\%)

9/13 (69\%)

9/13 (69\%)

8/13 (62\%)

$8 / 13(62 \%)$

6/13 (46\%)

6/13 (46\%)

$3 / 13$ (23\%)

3/13 (23\%)

2/13 (15\%)

(2011) [4] and further confirmed that AS patients with UPD have significantly higher BMI than AS patients with other underlying genetic abnormalities.

The patient was diagnosed with AS at the age of 16 months, earlier than in previous reports of UPD, allowing the parents to be given a correct prognosis and an explanation of delayed neurological developmental as well as the possibility of early interventional therapy. In addition, the parents were counseled that the child is at risk for obesity and its associated complications,

which could be managed with lifestyle adjustments. As the aberration was the result of a de novo occurrence, the parents were not counseled on the risk of recurrence for further pregnancies.

\section{Conclusions}

In this paper we report the case of a 16-month-old Hungarian boy affected by AS due to UPD. The early diagnosis of AS has great significance, it allows the parents to be given a correct prognosis and the possibility of early interventional therapy. The detection of UPD and reviewing the previous cases reported in the literature have also pivotal role, since it contributes to the deeper understanding of the phenotype-genotype correlation in AS for non-deletion subclasses. Our data suggest that AS patients with UPD have milder symptoms and higher BMI than AS patients with other underlying genetic abnormalities.

\section{Methods}

Cytogenetic analysis of the child and his parents was carried out with standard methods using $\mathrm{G}$ banding with the Cytovision imaging system. The results of the cytogenetic studies suggested UPD, and, therefore, further molecular genetic studies were carried out. Genomic DNA was extracted from venous blood of the index patient (III/1), his parents (II/1, II/2), his grandparents $(\mathrm{I} / 1, \mathrm{I} / 2, \mathrm{I} / 3, \mathrm{I} / 4)$ and his maternal aunts (II/3, II/4, II/5) [19]. Chromosome 15 segregation analysis with intragenic and extragenic markers for the fibrillin-1 gene was performed for all family members using amplified fragment length polymorphism analysis on an ALFexpress instrument [20]. To determine the molecular background and the recurrence risk, primers for the following microsatellite markers were used in the analysis: D15S119, D15S1028 and MMTS2.

\section{Consent}

Written informed consent was obtained from the patient's legal guardian for publication of this case report and accompanying images. A copy of the written consent is available for review by the Editor-in-Chief of this journal.

\section{Abbreviations}

AS: Angelman syndrome; PWS: Prader-Willi syndrome; IC: Imprinting center; UBE3A: Ubiquitin protein ligaseE3A gene; UPD: Uniparental disomy;

STR: Short tandem repeat; BMI: Body mass index.

Competing interests

The authors declare that they have no competing interest.

\section{Authors' contribution}

EH contributed to data collection and the first draft of the manuscript. $\mathrm{ZH}, \mathrm{Dl}$ and NN carried out the mutation analysis. GG and JS cared for the patient. LS, MS and EE were mentors who contributed equally to this work. All authors read and approved the final manuscript. 


\section{Acknowledgments}

TÁMOP-4.2.2.A-11/1/KONV-2012-0035 grant, TÁMOP-4.2.2/B-10/1/KONV-20100012 grant. Dr. László Sztriha received funds from the Marie Curie International Reintegration Grant (MIRG-CT-2005-030967) within the 6th European Community Framework Program. OTKA PD104782 2012-2015 grant, Nikoletta Nagy is supported by Janos Bolyai Scholarship 2011-2014.

\section{Author details}

${ }^{1}$ Department of Medical Genetics, University of Szeged, 4 Somogyi B. utca, H-6720, Szeged, Hungary. ${ }^{2}$ Department of Pediatrics and Child Health Centre, University of Szeged, Szeged, Hungary. ${ }^{3}$ Dermatological Research Group of the Hungarian Academy of Sciences, University of Szeged, Szeged, Hungary.

Received: 9 July 2013 Accepted: 10 August 2013

Published: 8 September 2013

\section{References}

1. Clayton-Smith J, Laan L: Angelman syndrome: a review of the clinical and genetic aspects. J Med Genet 2003, 40:87-95.

2. Williams CA, Beaudet AL, Clayton-Smith J, Knoll JH, Kyllerman M, Laan LA, Magenis RE, Moncla A, Schinzel AA, Summers JA, Wagstaff J: Angelman syndrome 2005: updated consensus for diagnostic criteria. Am J Med Genet 2006, 140:413-418.

3. Poyatos D, Guitart M, Gabau E, Brun C, Mila M, Vaquerizo J, MD C: Severe phenotype in Angelman syndrome resulting from paternal isochromosome 15. J Med Genet 2002, 39:4.

4. Tan WH, Bacino CA, Skinner SA, Anselm I, Barbieri-Welge R, Bauer-Carlin A, Beaudet AL, Bichell TJ, Gentile JK, Glaze DG, Horowitz LT, Kothare SV, Lee HS, Nespeca MP, Peters SU, Sahoo T, Sarco D, Waisbren SE, Bird LM: Angelman syndrome: mutations influence features in early childhood. Am J Med Genet 2011, 155:81-90.

5. Kim SR, Shaffer LG: Robertsonian translocations: mechanisms of formation, aneuploidy, and uniparental disomy and diagnostic considerations. Genet Test 2002, 6:163-168.

6. Freeman SB, May KM, Pettay D, Fernhoff PM, Hassold TJ: Paternal uniparentaldisomy in a child with a balanced 15;15 translocation and Angelman syndrome. Am J Med Genet 1993, 45:625-630

7. Tonk V, Schultz RA, Christian SL, Kubota T, Ledbetter DH, Wilson GN: Robertsonian $(15 q, 15 q)$ translocation in a child with Angelman syndrome: evidence of uniparentaldisomy. Am J Med Genet 1996, 66:426-428.

8. Ramsden S, Gaunt L, Seres-Santamaria A, Clayton-Smith J: A case of Angelman syndrome arising as a result of a de novo Robertsonian translocation. Acta Genet Med Gemellol 1996, 45:255-261

9. Guitart M, Escudero T, Gabau E, Dorminguez MC, Jimenez MD, Mila M, Coll MD: Two new cases of Angelman syndrome with a balanced 15;15 translocation and paternal uniparental disomy. Cytogenet Cell Genet 1997, 77:227.

10. Fridman C, Varela MC, Nicholls RD, Koiffmann CP: Unusual clinical features in an Angelman syndrome patient with uniparental disomy due to a translocation 15q15q. Clin Genet 1998, 54:303-308.

11. Robinson WP, Christian SL, Kuchinka BD, Peñaherrera MS, Das S, Schuffenhauer S, Malcolm S, Schinzel AA, Hassold TJ, Ledbetter DH: Somatic segregation errors predominantly contribute to the gain or loss of a paternal chromosome leading to uniparental disomy for chromosome 15. Clin Genet 2000, 57:349-358.

12. Bottani $A$, Robinson WP, DeLozier-Blanchet CD, Engel E, Morris MA, Schmitt B, Thun-Hohenstein L, Schinzel A: Angelman syndrome due to paternal uniparentaldisomy of chromosome 15: milder phenotype? Am J Med Genet 1994, 51:35-40.

13. Smith A, Marks R, Haan E, Dixon J, Trent RJ: Clinical features in 4 patients with Angelman syndrome resulting from paternal uniparental disomy. J Med Genet 1997, 34:426-429.

14. Moncla A, Malzac P, Voelckel MA, Auquier P, Girardot L, Mattei MG, Philip N, Mattei JF, Lalande M, Livet MO: Phenotype-genotype correlation in 20 deletion and non-deletion Angelman syndrome patients. Eur J Hum Genet 1999, 7:131-139.

15. Prasad C, Wagstaff J: Genotype and phenotype in Angelman syndrome caused by paternal UPD 15. Am J Med Genet 1997, 70:328-329.

16. Liehr T: Cases with uniparental disomy. http://www.fish.uniklinikum-jena.de/ UPD.html. [accessed 05/08/2013].

17. Lossie AC, Whitney MM, Amidon D: Distinct phenotypes distinguish the molecular classes of Angelman syndrome. J Med Genet 2001, 38:834-845
18. Varela MC, Kok F, Otto PA, Koiffmann CP: Phenotypic variability in Angelman syndrome: comparison among different deletion classes and between deletion and UPD subjects. Eur J Hum Genet 2004, 12:987-992.

19. Abrams DJ, Aronoff AR, Ann Berend S, Roa BB, Shaffer LG, Geier MR Prenatal diagnosis of a homologous Robertsonian translocation involving chromosome 15. Prenat Diagn 2011, 21:676-679.

20. Judge DP, Biery NJ, Dietz HC: Characterization of microsatellite markers flanking FBN1: utility in the diagnostic evaluation for Marfan syndrome. Am J Med Genet 2001, 99:39-47.

doi:10.1186/1755-8166-6-35

Cite this article as: Horváth et al:: Early detection of Angelman syndrome resulting from de novo paternal isodisomic 15q UPD and review of comparable cases. Molecular Cytogenetics 2013 6:35.

\section{Submit your next manuscript to BioMed Central and take full advantage of:}

- Convenient online submission

- Thorough peer review

- No space constraints or color figure charges

- Immediate publication on acceptance

- Inclusion in PubMed, CAS, Scopus and Google Scholar

- Research which is freely available for redistribution 


\title{
Journal of Child Neurology \\ http://jcn.sagepub.com/
}

Nemaline Myopathy Type 2 (NEM2): Two Novel Mutations in the Nebulin (NEB) Gene

Anna Gajda, Emese Horváth, Tibor Hortobágyi, Gyurgyinka Gergev, Hajnalka Szabó, Katalin Farkas, Nikoletta Nagy, Márta Széll and László Sztriha

J Child Neurol published online 20 September 2013

DOI: $10.1177 / 0883073813494476$

The online version of this article can be found at:

http://jcn.sagepub.com/content/early/2013/09/19/0883073813494476

\author{
Published by: \\ (\$)SAGE \\ http://www.sagepublications.com
}

Additional services and information for Journal of Child Neurology can be found at:

Email Alerts: http://jcn.sagepub.com/cgi/alerts

Subscriptions: http://jcn.sagepub.com/subscriptions

Reprints: http://www.sagepub.com/journalsReprints.nav

Permissions: http://www.sagepub.com/journalsPermissions.nav

>> OnlineFirst Version of Record - Sep 20, 2013

What is This? 


\title{
Nemaline Myopathy Type 2 (NEM2): Two Novel Mutations in the Nebulin (NEB) Gene
}

Journal of Child Neurology $00(0)$ I-4

(C) The Author(s) 2013

Reprints and permission:

sagepub.com/journalsPermissions.nav DOI: I0.II77/08830738I3494476 jcn.sagepub.com

\author{
Anna Gajda, MD', Emese Horváth, MD², Tibor Hortobágyi, MD, PhD³, \\ Gyurgyinka Gergev, MA ${ }^{1,4}$, Hajnalka Szabó, MD, PhD', Katalin Farkas, BSc ${ }^{5}$, \\ Nikoletta Nagy, MD, PhD ${ }^{2,5}$, Márta Széll, MSc, PhD, DSc ${ }^{2,5}$, and \\ László Sztriha, MD, PhD, DSc'
}

\begin{abstract}
Nemaline myopathy is a type of the heterogeneous group of congenital myopathies. Generalized hypotonia, weakness, and delayed motor development are the main clinical features of the typical congenital form. Histopathology shows characteristic nemaline rods in the muscle biopsy. Mutations in at least 7 genes, including nebulin gene (NEB), proved to be responsible for this muscle disease. We present a boy with nemaline myopathy type 2 (NEM2) caused by compound heterozygosity for 2 novel mutations, a deletion and a duplication in the NEB gene. The deletion was inherited from the father and the duplication from the mother. Testing all family members supports genetic counseling.
\end{abstract}

\section{Keywords \\ congenital myopathy, hypotonia, nebulin}

Received April 9, 20I3. Received revised April 26, 20I3. Accepted for publication May 28, 2013.

Congenital myopathies are a group of genetic muscle disorders with clinical, pathologic, and molecular heterogeneity. ${ }^{1}$ Nemaline myopathy is a pathologically well-defined subgroup of congenital myopathies characterized by the presence of rodlike structures in the muscle fibers. ${ }^{2}$ The disease presents a wide range of clinical variability and severity, although generalized hypotonia, muscle weakness, feeding difficulties, and delay of motor milestones are almost always present. ${ }^{2}$ All molecularly characterized forms of nemaline myopathy are autosomal, but inheritance can be recessive or dominant, and singleton cases could arise from de novo dominant mutations. ${ }^{2,3}$ To date, 7 genes have been linked to this condition: $\alpha$-tropomyosin (TPM3), nebulin (NEB), skeletal muscle $\alpha$-actin (ACTA1), $\beta$ tropomyosin (TPM2), muscle troponin T1 (TNNT1), cofilin-2 (CFL2) and the recently identified KBTBD13 gene, whose function is still unknown. ${ }^{2-4}$

Disease resulting from mutations in the $N E B$ gene is classified as nemaline myopathy type 2 (NEM2; OMIM 256030), the most common form of nemaline myopathy. ${ }^{2}$ NEM2 is a rare autosomal recessive condition characterized by early-onset muscle weakness, which is most pronounced in the axial muscles and proximal limb-girdles. Weakness in facial and bulbar muscles commonly results in dysarthria. ${ }^{5}$ The course of the disease is nonprogressive or slowly progressive and life expectancy depends on the severity of respiratory muscle weakness.
Mechanical ventilation is necessary for some patients and orthopedic complications are frequent. ${ }^{6}$ Mental development and intelligence are typically within the normal range. ${ }^{6}$ In this report, we present the clinical and histologic findings in a patient suffering from NEM2 and describe compound heterozygosity for 2 novel mutations in the $N E B$ gene.

\section{Case Report}

\section{Clinical Presentation}

The patient, a boy, was born at term from a fourth uneventful pregnancy. Birth weight was $3450 \mathrm{~g}$ and Apgar scores were 9 and 10 at 5 and 10 minutes, respectively. Floppiness and weak

\footnotetext{
' Department of Pediatrics, University of Szeged, Szeged, Hungary

${ }^{2}$ Department of Medical Genetics, University of Szeged, Szeged, Hungary

${ }^{3}$ Department of Neuropathology, University of Debrecen, Debrecen, Hungary

${ }^{4}$ 2nd Department of Pediatrics, Semmelweis University, Budapest, Hungary

${ }^{5}$ Dermatological Research Group of the Hungarian Academy of Sciences,

University of Szeged, Szeged, Hungary
}

\section{Corresponding Author:}

Anna Gajda, MD, Department of Pediatrics, University of Szeged, I4-I 5 Korányi fasor, H-6720 Szeged, Hungary.

Email: annagajd@gmail.com 


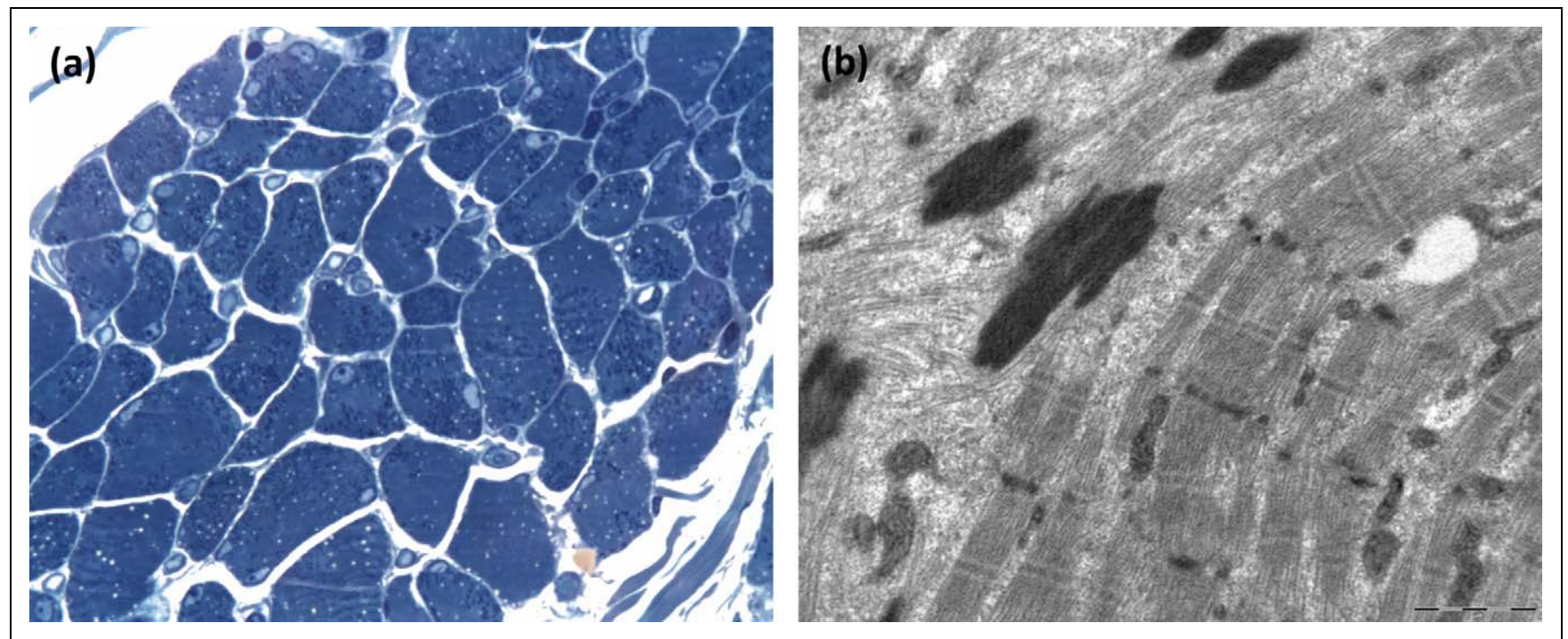

Figure I. Nemaline myopathy. (a) Toluidin blue staining of plastic-embedded semithin section shows numerous rod structures in the muscle fibers. (b) Electron microscopy reveals that the rods are electron-dense structures.

cry were noticed in the neonatal period. Generalized hypotonia, weakness, and delayed acquisition of motor milestones were observed in early childhood. He began to walk with support at the age of 2 years. Deep tendon reflexes were reduced. There was no fasciculation in the tongue. He suffered also from recurrent respiratory tract infections. The serum creatine kinase activity was normal. The optic fundus and brain magnetic resonance imaging (MRI) were also normal. Tandem mass spectrometry and urine gas chromatography screening showed no evidence of inborn error of metabolism. Nerve conduction velocity was normal, and electromyography did not show any abnormalities. There was no homozygous deletion in exons 7 and 8 of the SMN1 (Survival of Motor Neuron 1) gene. The possibility of a congenital myopathy emerged and muscle biopsy was performed at the age of 4 years. Severe respiratory tract infection and pneumonia led to respiratory failure, later requiring tracheostomy and mechanical ventilation. His condition subsequently improved; however, he needs ventilatory support during sleep. Cardiologic examination did not show any abnormalities. The patient's cognitive abilities were appropriate for his age.

The patient's parents and his 3 siblings (a brother and 2 sisters) are asymptomatic.

Informed consent was requested from the parents prior to the muscle biopsy and molecular genetic studies.

\section{Muscle Biopsy}

The histologic workup of the muscle biopsy tissue followed standard procedures. The majority of the muscle fibers were hypoplastic or atrophic with large variation in fiber size. Fiber necrosis, regeneration, phagocytosis, or inflammatory cell infiltration were not noted. Gomori's trichrome technique detected prominent red-stained inclusion bodies in the fibers with variation in number and distribution (Figure 1a). Toluidin blue- stained sections showed rod-shaped particles in the fibers. Electron microscopy revealed that the rods appeared as electron-dense structures localized mainly along the thickened Z-lines (Figure 1B). These rod-shaped particles were identified as nemaline rods/bodies, and these findings were consistent with the diagnosis of nemaline myopathy.

\section{Genetics}

In view of the morphologic findings, a search was initiated in collaboration with the commercial diagnostic company Centogene $\mathrm{GmbH}$ (Rostock, Germany) to find the molecular genetic etiology of nemaline myopathy in this child. Tests for ACTA1 and TPM3 were negative. Eventual testing of the $N E B$ gene revealed 2 previously unreported heterozygous mutations: a deletion (c.24527_24528delCT p.P8176fsX8179; Figure 2A) in exon 174 and a duplication (c.24250_24253dupGTCA p.T8085fsX8100; Figure 2B) in exon 171. These mutations result in a frameshift and a premature termination codon, respectively, presumably leading to truncated nebulin protein. Further testing of the parents revealed that the father carries the deletion and the mother has the heterozygous duplication (Figure 3). One of the 2 sisters of the patient carries wildtype alleles, whereas another sister and the brother are heterozygous for the duplication (Figure 3). Thus, the clinically unaffected family members carry either wild-type alleles or only 1 of the mutant alleles; either the duplication or the deletion. The patient, however, is a compound heterozygous carrier of both mutations.

\section{Discussion}

Nemaline myopathies are a clinically and molecularly heterogeneous group of congenital myopathies. ${ }^{1-3}$ The combination of characteristic clinical and histopathologic features are 


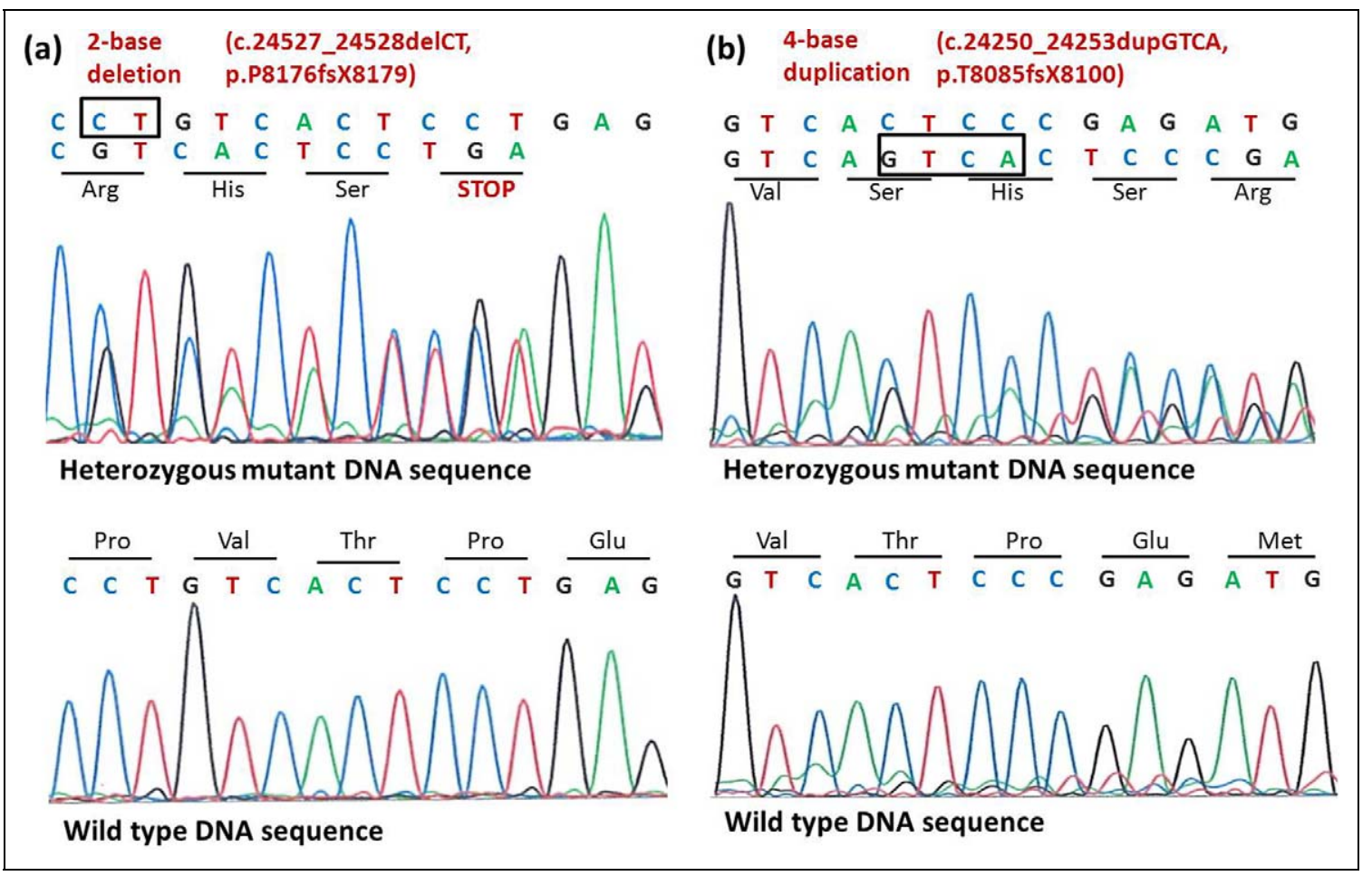

Figure 2. Identification of 2 novel mutations (I deletion and I duplication) in the NEB gene. Direct sequencing of DNA isolated from the affected patient (II/4) revealed (A) a 2-base deletion (c.24527_24528delCT) in exon 174 of the NEB gene resulting in a premature termination codon (p.P8I76fsX8I79) in the translated sequence and (B) a 4-base duplication (c.24250_24253dupGTCA) in exon I7I of the NEB gene, resulting in frameshift (p.T8085fs 88100$)$ in the translated sequence.

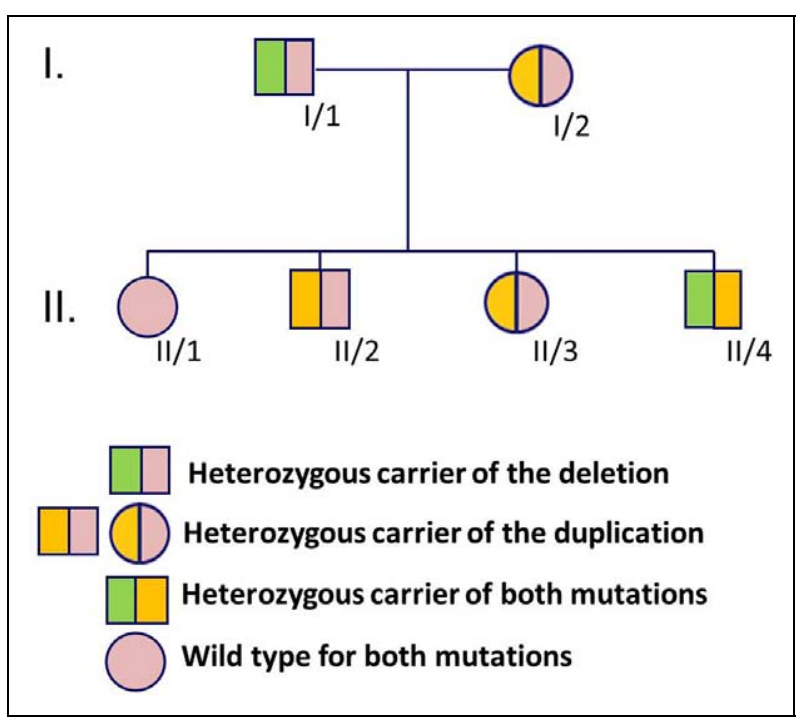

Figure 3. Genetic screening of the affected family. The patient (II/4) and his clinically unaffected father $(I / I)$ carry the deletion in heterozygous form, whereas the other unaffected family members $(I / 2, I I / I, I I / 2$, II/3) carry the wild-type allele. The patient (II/4) and his clinically unaffected mother (I/2), brother (II/2), and sister (II/3) carry the duplication in heterozygous form, whereas the other unaffected family members $(I / I, I I / I)$ carry the wild-type allele. These results suggest that the deletion is of paternal origin and the duplication is of maternal origin. The patient (II/4) is, thus, a compound heterozygote for these 2 novel mutations. diagnostic for the disorder in most cases. ${ }^{1-3}$ The presence of red inclusions detected with Gomori trichrome staining and of rodshaped particles in toluidine blue-stained tissue from the patient strongly suggest nemaline myopathy. ${ }^{1-3}$ Ultrastructural studies reveal nemaline bodies as electron-dense, rod-shaped structures appearing as thickened Z-disks. ${ }^{1-3}$ Muscle imaging by magnetic resonance can be helpful to visualize the pattern of selective muscle involvement and guide in localizing the site of the biopsy. ${ }^{7,8}$

The workup of a case with nemaline myopathy is further complicated by its heterogeneous genetic background: 7 known causative genes have been linked to this condition and both autosomal dominant and recessive inheritance has been observed. ${ }^{2,9}$ Six of these genes encode proteins associated with sarcomeric thin filaments. ${ }^{2}$ Recessive mutations in the $N E B$ gene, located on chromosome $2 \mathrm{q} 22-23$, are the most commonly recognized cause of the disease. ${ }^{2,4}$ This gene has 182 exons, and missense, nonsense, and frameshift mutations have been reported. ${ }^{10}$ Hotspots have not been found and many patients proved to be compound heterozygotes for 2 mutations within the gene. ${ }^{2,10}$ The nebulin protein has a wide range of functions, including thin filament length specification and regulation of muscle contraction. ${ }^{4}$

The clinical, histologic, and molecular genetic findings in our patient are consistent with the typical congenital form of nemaline myopathy type 2 , caused by mutations in the $N E B$ gene. $^{2}$ Compound heterozygosity for 2 novel mutations was 
found. A 2-base deletion (c.24527_24528delCT, p.P8176fsX8179) was inherited from the father and a 4-base duplication (c.24250_24253dupGTCA, p.T8085fsX8100) from the mother. These novel mutations led to a translational frameshift and a premature termination codon in the respective translated sequences and thus, presumably, to truncated nebulin protein.

Nemaline myopathy is a debilitating condition and further research is warranted in order to explore the details of the molecular pathology of this disorder. These efforts are complicated by the heterogenic molecular background of the disease and the fact that certain genes encode very large proteins like nebulin. Molecular diagnosis, however, becomes available for more and more patients supporting preimplantation or prenatal diagnosis for subsequent pregnancies. ${ }^{2}$ This case report extends the genetic profile of nemaline myopathy with 2 previously unreported mutations in the $N E B$ gene.

\section{Acknowledgments}

The authors are grateful for Centogene GmbH (Rostock, Germany) for performing the mutation analysis of the ACTA1, TPM3, and NEB genes.

\section{Author Contributions}

AG and EH contributed to data collection and the first draft of the manuscript. TH performed the evaluation of the muscle biopsy. GG and HS cared for the patient and KF and NN carried out the mutation analysis of the parents and family members. MS and LS were mentors who contributed equally to this work. AG and EH also contributed equally to this work.

\section{Declaration of Conflicting Interests}

The authors declared no potential conflicts of interest with respect to the research, authorship, and/or publication of this article.

\section{Funding}

The authors disclosed receipt of the following financial support for the research, authorship, and/or publication of this article: Supported by
TÁMOP-4.2.2.A-11/1/KONV-2012-0035 grant and TÁMOP-4.2.2/ B-10/1/KONV 2010-0012 grant.

\section{Ethical Approval}

The writing/research of this article did not require ethical approval.

\section{References}

1. Nance JR, Dowling JJ, Gibbs EM, Bönnemann JJ. Congenital myopathies: an update. Curr Neurol Neurosci Rep. 2012;12: 165-174.

2. Wallgren-Pettersson C, Sewry CA, Nowak KJ, Laing NG. Nemaline myopathies. Semin Pediatr Neurol. 2011;18:230-238.

3. North KN. Clinical approach to the diagnosis of congenital myopathies. Semin Pediatr Neurol. 2011;18:216-220.

4. Labeit $\mathrm{S}$, Ottenheijm CA, Granzier H. Nebulin, a major player in muscle health and disease. FASEB J. 2011;25:822-829.

5. Wallgren-Pettersson C.Congenital nemaline myopathy. A clinical follow-up of twelve patients. J Neurol Sci. 1989;89:1-14.

6. Wallgren-Pettersson C, Laing NG. Report of the 70th ENMC International Workshop: nemaline myopathy, 11-13 June 1999, Naarden, The Netherlands. Neuromuscul Disord. 2000;10: 299-306.

7. Fischer D, Herasse M, Ferreiro A, et al. Muscle imaging in dominant core myopathies linked or unlinked to the ryanodine receptor 1 gene. Neurology. 2006;67:2217-2220.

8. Mercuri E, Pichiecchio A, Allsop J, et al. Muscle MRI in inherited neuromuscular disorders: past, present, and future. J Magn Reson Imaging. 2007;25:433-440.

9. Wallgren-Pettersson C, Pelin K, Hilpela P, et al. Clinical and genetic heterogeneity in autosomal recessive nemaline myopathy. Neuromuscul Disord. 1999;9:564-572.

10. Wallgren-Pettersson C, Donner K, Sewry C, et al. Mutations in the nebulin gene can cause severe congenital nemaline myopathy. Neuromuscul Disord. 2002;12:674-679. 


\section{Identification of a novel missense GLRA1 gene mutation in hyperekplexia: a case report}

Emese Horváth ${ }^{1}$

Email: horvath.emese@med.u-szeged.hu

Katalin Farkas ${ }^{2}$

Email: farkaskatalin88@gmail.com

Ágnes Herczegfalvi ${ }^{3}$

Email: $\underline{\text { Herczegfalvi@ bethesda.hu }}$

Nikoletta Nagy ${ }^{1,2^{*}}$

*Corresponding author

Email: nikoletta.nagy@gmail.com

Márta Szél1 ${ }^{1,2}$

Email: szell.marta@med.u-szeged.hu

${ }^{1}$ Department of Medical Genetics, University of Szeged, Somogyi utca 4, H-6720, Szeged, Hungary

${ }^{2}$ Dermatological Research Group of the Hungarian Academy of Sciences, University of Szeged, Korányi fasor 6, H-6720, Szeged, Hungary

${ }^{3}$ Pál Heim Children's Hospital, Üllői út 86, H-1089, Budapest, Hungary 


\section{ABSTRACT}

Introduction: Hereditary hyperekplexia (HKPX) is a neurological disorder characterized by excessive startle responses with violent jerking to noise or touch, stiffening of the trunk and limbs, clenching fists and attacks of a high-frequency trembling. Hyperekplexia has a heterogeneous genetic background with several identified causative genes and demonstrates both dominant and recessive inheritance. Mutations in the glycine receptor alpha 1 subunit gene (GLRA1) occur in about $30 \%$ of hyperekplexia cases.

Case presentation: In this study, we report a Hungarian boy whose abnormal movements, muscle stiffness and convulsions were first noted when he was 4 days old. Neurological and electrophysiological investigation suggested the clinical diagnosis of hyperekplexia.

Conclusions: Direct sequencing of the coding regions and the flanking introns of the GLRAI gene revealed a novel heterozygous missense mutation (c.211A/T, p.Ile71Phe). Genetic screening of the patient's family revealed that the clinically unaffected parents and sister do not carry the mutation suggesting that the identified sequence change is a de novo mutation. Since hyperekplexia can have severe consequences, including sudden infant death due to laryngospasm and cardiorespiratory failure, identification of the causative genetic alteration(s) of the disease is high priority. Such knowledge is necessary for prenatal diagnosis, which would allow informed family planning and greater parental sensitivity to hyperekplexia 1-associated risks.

Key words: stiff-baby syndrome, hereditary hyperekplexia, GLRA1 gene, missense mutation 


\section{INTRODUCTION}

Hereditary hyperekplexia (HKPX, ORPHA3197) is an early-onset neurological disorder characterized by excessive startle responses with violent jerking to sudden, unexpected auditory or tactile stimuli [1,2]. Hyperekplexia usually develops shortly after birth: neonates have prolonged periods of stiffness, clenching fists and attacks of a high-frequency trembling $[1,2]$. Hyperekplexia can have severe consequences such as sudden infant death due to laryngospasm and cardiorespiratory failure [1]. The symptoms tend to resolve after infancy; however adults may have increased startle-induced falls or nocturnal muscle jerks [1].

Hyperekplexia has a heterogeneous genetic background [3,4]. Different mutations in several genes involved in glycinergic neurotransmission can lead to hyperekplexia, and the disease exhibits both autosomal recessive and dominant inheritance [3,4]. Mutations in the glycine receptor alpha 1 subunit gene (GLRA1) result in hyperekplexia 1 (OMIM149400) and occur in about $30 \%$ of hyperekplexia 1 cases [5]. Mutations in other genes such as the glycine receptor beta subunit gene (GLRB; HKPX2, OMIM614619) [6], the glycine transporter solute carrier family 6 member 5 gene (SLC6A5; HKPX3, OMIM614618) [7], the glycine receptor locator gephyrin gene (GPHN; OMIM603930) [8] and the postsynaptic glycine enhancer collybistin gene (ARHGEF9; OMIM300429) have also been associated with this clinical condition[9].

In this paper, we present the clinical and genetic investigations of a Hungarian family affected by hyperekplexia 1 and the identification of a novel disease-causing heterozygote missense mutation of the GLRA1 gene.

\section{CASE PRESENTATION}

A male neonate was born on term at the $40^{\text {th }}$ week of gestation by cesarean section delivery after an uneventful pregnancy. His birth weight was $3990 \mathrm{~g}$ and Apgar score was 9/10. At day 1 post- 
term, he developed pneumothorax and was admitted to the perinatal intensive care unit for extra oxygen and parenteral fluid therapy. At day 4 post-term, abnormal movements, stiffness of the muscles and convulsions were observed, and phenobarbital therapy was initiated. Neurological investigation suggested developmental disturbances of the basal moving circle. At day 11 postterm, he was hospitalized in a developmental neurology ward. Examination did not identify hypoxia-induced regulatory abnormalities. The observed recurrent muscular hypertonia was attributed to a suspected ion channel disorder and carbamazepine therapy was initiated.

Ultrasonography of the hip indicated the possibility of dysplasia on the left side, and ultrasonography of the abdomen revealed bilateral mild pyelectasis. The results of neurosonography, electroencephalography and magnetic resonance imaging of the head did not indicate any abnormalities of the central nervous system.

After pre-test genetic counseling was performed and written informed consent was obtained from the parents, a blood sample was taken from the patient, his clinically unaffected sister and the clinically unaffected parents for genetic investigation. Genomic DNA was isolated using a BioRobot EZ1 DSP Workstation (QIAGEN; Hilden, Germany). The coding regions of the GLRA1 gene and the flanking introns were amplified and sequenced (using primers sequences obtained from the UCSC Genome Browser, www.genome.ucsc.edu). Molecular genetic investigation was carried out by the amplification and direct sequencing of the GLRAl gene. Having identified the putative causative mutation in the patient (II/1), mutation screening of the unaffected family members (I/1, I/2 and II/1) was carried out. Direct sequencing of the coding regions and the flanking introns of the GLRAl gene revealed a novel heterozygous missense mutation (c.211A/T, p.Ile71Phe) in exon 3 (Figure 1a). Mutation was confirmed by a second validation method, re-sequencing. Genetic screening of the affected family revealed that the clinically unaffected parents (I/1 and I/2) and the unaffected sister (II/1) did not carry the 
mutation, suggesting that the identified novel sequence alteration is a de novo mutation in the patient (Figure 1d).

\section{CONCLUSIONS}

In this paper, we report a Hungarian patient with hyperekplexia, a potentially fatal neurological disorder characterized by pronounced startle responses. Abnormal movements, stiffness and convulsions were first noted in the patient at day 4 post-term, which correlates well with the early-onset of the disease. The initial severe symptoms of the patient were attenuated by carbamazepine therapy and physiotherapy and subsequently diminished with age.

Hyperekplexia has been linked to genetic alterations in genes involved in an inhibitory neurotransmitter, glycine neurotransmission [3,4]. GLRA1 mutations account for approximately $30 \%$ of all hyperekplexia cases [5]. Both compound heterozygous patients and homozygous mutation carriers have been described in the literature for recessive forms of the disease [10]. A heterozygous missense mutation (c.211A/T, p.Ile71Phe) was detected in the patient in exon 3 of the GLRA1 gene, establishing the diagnosis of hyperekplexia 1 and suggesting that the mutation is an autosomal dominant form of the disease. As the non-coding regions of the GLRAl gene were not examined, we cannot exclude the possibility of second mutation that represents a recessive form in our patient.

The GLRAl gene encodes a neurotransmitter-gated ion channel transmembrane protein with three transmembrane segments (TM1-3) [11,12]. Binding of glycine to its receptor increases the chloride conductance, produces hyperpolarization and, thus, the inhibition of neuronal firing $[11,12]$. Previous studies have attributed dominant forms of hyperekplexia 1 to mutations within the pore-lining transmembrane segment (TM2) and adjacent regions, recessive forms to mutations within the other transmembrane segments (TM1 and TM3), and the null allele of the 
GLRA1 gene to the deletion of exons 1-7 [11,12]. The novel heterozygous missense mutation (p.Ile71Phe) reported here is located close to the $\mathrm{NH}_{2}$-terminal of the GLRA1 protein outside the transmembrane segments (Figure 1b), in a highly conserved region (Figure 1c). The mutation is located in a region that is not predicted or known to be a functional domain of the GLRA1 protein. Other missense mutations have been detected in this region in patients with hyperekplexia 1 (p.Trp68Cys and p.Arg72His) [3], and in spasmodic mouse (p.Ala52Ser) [13]. The functional analysis performed on the spasmodic mouse model suggested that the p.Ala52Ser missense mutation results in reduced glycine sensitivity [13]. Recessive mutations in the Nterminal regions or majority of recessive hyperekplexia mutations have trafficking defects. Dominant mutations can may cause reduce glycine sensitivity. Based on these previous studies, we hypothesize that the reported novel missense mutation detected in our Hungarian patient might lead to reduced glycine sensitivity as well.

It is also interesting to note, that previously reported missense mutations in this region (human p.Trp68Cys and p.Arg72His and murine p.Ala52Ser) are all associated with the recessive form of hyperekplexia 1 , indicating the possibility that other undetected mutations might contribute to the clinical symptoms of our Hungarian patient.

Having identified the putative causative mutation in the index patient, clinically unaffected family members were also screened and shown to carry only wildtype sequence of the GLRAI gene. Our results suggest that this novel missense sequence change (c.211A/T, p.Ile71Phe) identified in the index patient is a de novo mutation, however the vast majority of GLRA1 mutations are inherited from parents in domimnant, recessive and compound heterizygote fashions $[3,14,15]$.

The consequences of the hyperekplexia 1 can be severe, warranting further efforts to elucidate the nature of the disease despite the complications implicit with the heterogenic genetic background. 
With the identification of the underlying genetic abnormalities, prenatal screening is available for affected families and allows informed family planning. In the future, knowledge of the genetic causes of this life-threatening disease may also contribute to the development of novel therapeutic alternatives.

\section{CONSENT}

Written informed consent was obtained from the patient's legal guardian(s)/parent(s) for publication of this case report and any accompanying images. A copy of the written consent is available for review by the Editor-in-Chief of this journal.

\section{LIST OF ABBREVIATIONS}

HKPX: hereditary hyperekplexia

GLRA1: glycine receptor alpha 1 subunit gene

\section{COMPETING INTERESTS}

The authors declare that they have no competing interest.

\section{AUTHOR'S CONTRIBUTIONS}

EH, KF, ÁH, NN, MS met the ICMJE criteria for authorship.

EH contributed to data collection and the first draft of the manuscript.

$\mathrm{KF}$ and $\mathrm{NN}$ carried out the mutation analysis.

ÁH cared for the patient.

MS was mentors who contributed equally to this work. 


\section{ACKNOWLEDGMENTS}

TÁMOP-4.2.2.A-11/1/KONV-2012-0035 grant, TÁMOP-4.2.2/B-10/1/KONV-2010-0012 grant. 


\section{REFERENCES}

1. Ryan SG, Dixon MJ, Nigro MA, Kelts KA, Markand ON, Terry JC, Shiang R, Wasmuth JJ, O'Connell P: Genetic and radiation hybrid mapping of the hyperekplexia region on chromosome 5q. Am J Hum Genet 1992, 51:1334-1343.

2. Kirstein L, Silfverskiold BP: A family with emotionally precipitated 'drop seizures'. Acta Psychiat Neurol Scand 1958, 33:471-476.

3. Harvey RJ, Topf M, Harvey K, Rees MI: The genetics of hyperekplexia: more than startle! Trends Genet 2008, 24:439-447.

4. James VM, Gill JL, Topf M, Harvey RJ: Molecular mechanisms of glycine transporter GlyT2 mutations in startle disease. Biol Chem 2012, 393:283-289.

5. Rees MI, Andrew M, Jawad S, Owen MJ: Evidence for recessive as well as dominant forms of startle disease (hyperekplexia) caused by mutations in the alpha-1 subunit of the inhibitory glycine receptor. Hum Molec Genet 1994, 3:2175-2179.

6. Al-Owain M, Colak D, Al-Bakheet A, Al-Hashmi N, Shuaib T, Al-Hemidan A, Aldhalaan H, Rahbeeni Z, Al-Sayed M, Al-Younes B, Ozand PT, Kaya N: Novel mutation in GLRB in a large family with hereditary hyperekplexia. Clin Genet 2012, 81:479-484. 
7. Rees MI, Harvey K, Pearce BR, Chung SK, Duguid IC, Thomas P, Beatty S, Graham GE, Armstrong L, Shiang R, Abbott KJ, Zuberi SM, Stephenson JB, Owen MJ, Tijssen MA, van den Maagdenberg AM, Smart TG, Supplisson S, Harvey RJ: Mutations in the gene encoding GlyT2 (SLC6A5) define a presynaptic component of human startle disease. Nature Genet 2006, 38:801-806.

8. Reiss J, Gross-Hardt S, Christensen E, Schmidt P, Mendel RR, Schwarz G: A mutation in the gene for the neurotransmitter receptor-clustering protein gephyrin causes a novel form of molybdenum cofactor deficiency. Am J Hum Genet 2001, 68:208-213.

9. Harvey K, Duguid IC, Alldred MJ, Beatty SE, Ward H, Keep NH, Lingenfelter SE, Pearce BR, Lundgren J, Owen MJ, Smart TG, Lüscher B, Rees MI, Harvey RJ: The GDP-GTP exchange factor collybistin: as essential determinant of neuronal gephyrin clustering. J Neurosci 2004, 24:5816-5826.

10. Humeny A, Bonk T, Becker K, Jafari-Boroujerdi M, Stephani U, Reuter K, Becker CM: A novel recessive hyperekplexia allele GLRA1 (S231R): genotyping by MALDI-TOF mass spectrometry and functional characterisation as a determinant of cellular glycine receptor trafficking. Europ J Hum Genet 2002, 10:188-196.

11. Lynch JW: Molecular structure and function of the glycine receptor chloride channel. Physiol Rev 2004, 84:1051-1095. 
12. Becker K, Hohoff C, Schmitt B, Christen HJ, Neubauer BA, Sandrieser T, Becker CM: Identification of the microdeletion breakpoint in a GLRA1null allele of Turkish hyperekplexia patients. Hum Mutat 2006, 27:1061-1062.

13. Saul B, Schmieden V, Kling C, Mülhardt C, Gass P, Kuhse J, Becker CM: Point mutation of glycine receptor alpha 1 subunit in the spasmodic mouse affects agonist responses. FEBS Lett 1994, 350:71-76.

14. Rees MI, Lewis TM, Vafa B, Ferrie C, Corry P, Muntoni F, Jungbluth H, Stephenson JB, Kerr M, Snell RG, Schofield PR, Owen MJ: Compound heterozygosity and nonsense mutations in the alpha(1)-subunit of the inhibitory glycine receptor in hyperekplexia. Hum Genet 2001, 109:267-270.

15. Chung SK, Vanbellinghen JF, Mullins JG, Robinson A, Hantke J, Hammond CL, Gilbert DF, Freilinger M, Ryan M, Kruer MC, Masri A, Gurses C, Ferrie C, Harvey K, Shiang R, Christodoulou J, Andermann F, Andermann E, Thomas RH, Harvey RJ, Lynch JW, Rees MI: Pathophysiological mechanisms of dominant and recessive GLRA1 mutations in hyperekplexia. J Neurosci 2010, 30:9612-9620. 


\section{FIGURE LEGENDS}

Figure 1. Identification of a novel mutation in the GLRA1 gene and genetic screening of the affected family. (a) Direct sequencing of patient (II/2) DNA revealed a novel heterozygous missense mutation in exon 3 of the GLRAI gene. (b) The clinically unaffected family members (I/1, I/2 and II/1) carry only the wildtype sequence, suggesting a de novo mutation. (c) Comparison of GLRA1 protein sequences in the region of the mutation (p.Ile71Phe) from different species indicates that the region is highly conserved. (d) Genetic analysis of the affected family suggests that the identified sequence alteration is a de novo mutation. 


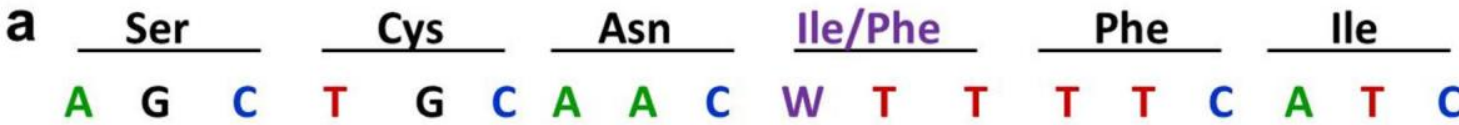

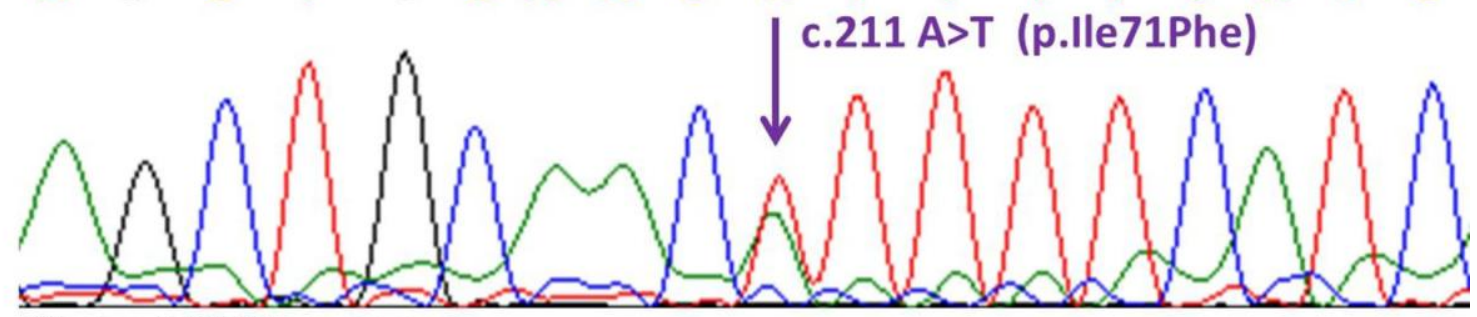

Mutant DNA sequence

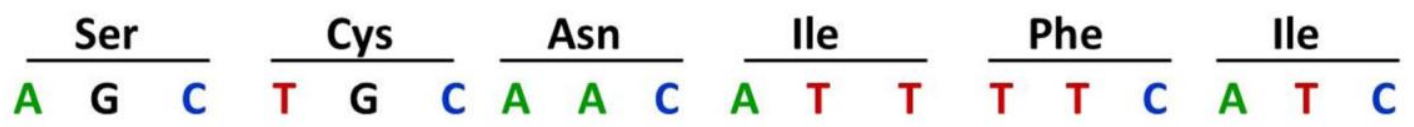

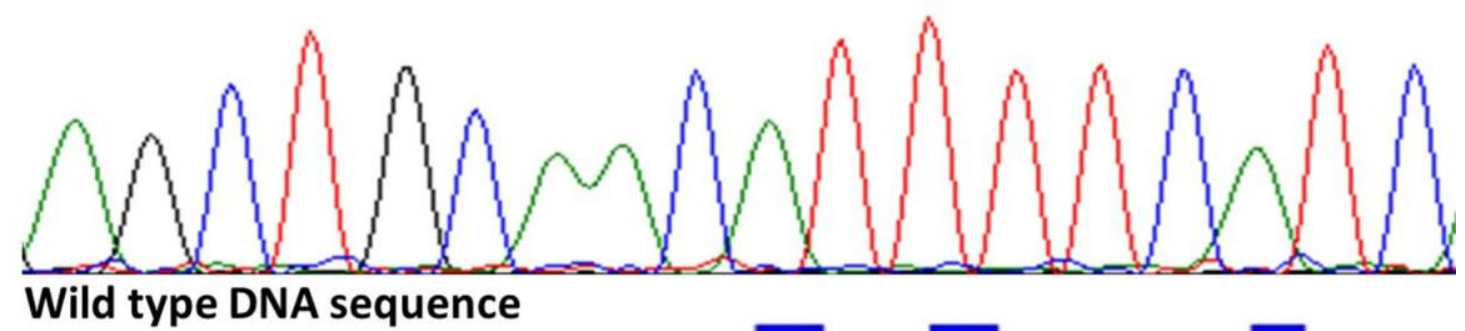

b

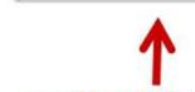

p. Ile 71 Phe

C

Homo sapiens

${ }_{17}^{\text {Pan troglodytes }}$

2. Mus musculus

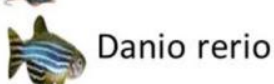
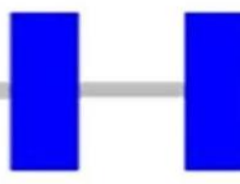

Transmembrane domain

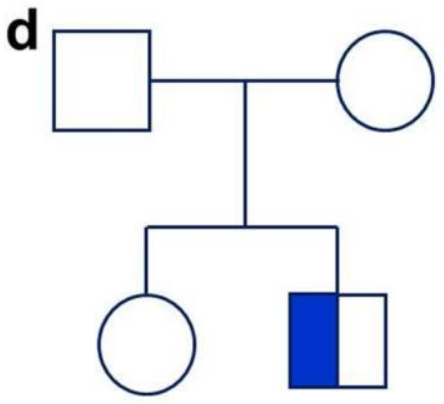

